\title{
Catalysis by the Non-Heme Iron(II) Histone Demethylase PHF8 Involves Iron Center Rearrangement and Conformational Modulation of Substrate Orientation
}

\author{
Shobhit S. Chaturvedi, ${ }^{\dagger}$ Rajeev Ramanan, ${ }^{\dagger}$ Nicolai Lehnert, ${ }^{\ddagger}$ Christopher J. Schofield, ${ }^{\S}$
} Tatyana G. Karabencheva-Christova, ${ }^{*}{ }^{\dagger}$ (1) and Christo Z. Christov ${ }^{*}, \dagger$

${ }^{\dagger}$ Department of Chemistry, Michigan Technological University, Houghton, Michigan 49931, United States

${ }^{\ddagger}$ Department of Chemistry and Department of Biophysics, University of Michigan, Ann Arbor, Michigan 48109, United States

${ }^{\S}$ The Chemistry Research Laboratory, University of Oxford, Mansfield Road, Oxford OX1 5JJ, U.K.

Supporting Information

ABSTRACT: PHF8 (KDM7B) is a human non-heme 2oxoglutarate (2OG) JmjC domain oxygenase that catalyzes the demethylation of the $\mathrm{di} / \mathrm{mono}-\mathrm{N}^{\varepsilon}$-methylated $\mathrm{K} 9$ residue of histone H3. Altered PHF8 activity is linked to genetic diseases and cancer; thus, it is an interesting target for epigenetic modulation. We describe the use of combined quantum mechanics/molecular mechanics (QM/MM) and molecular dynamics (MD) simulations to explore the mechanism of PHF8, including dioxygen activation, 2OG binding modes, and substrate demethylation steps. A PHF8 crystal structure manifests the $2 \mathrm{OG} \mathrm{C}-1$ carboxylate bound to iron in a nonproductive orientation, i.e., trans to His247. A ferryl-oxo intermediate formed by activating dioxygen bound to the vacant site in this complex would be nonproductive, i.e., "off-line" with respect to reaction with $\mathrm{N}^{\varepsilon}$-methylated $\mathrm{K}$. We show rearrangement of the "off-line" ferryl-oxo intermediate to a productive "in-line" geometry via a solvent exchange reaction (called "ferryl-flip") is energetically unfavorable. The calculations imply that movement of the 2OG C-1 carboxylate prior to dioxygen binding at a five-coordination stage in catalysis proceeds with a low barrier, suggesting that two possible 2 OG C-1 carboxylate geometries can coexist at room temperature. We explored alternative mechanisms for hydrogen atom transfer and show that second sphere interactions orient the $\mathrm{N}^{\varepsilon}$-methylated lysine in a conformation where hydrogen abstraction from a methyl $\mathrm{C}-\mathrm{H}$ bond is energetically more favorable than hydrogen abstraction from the $\mathrm{N}-\mathrm{H}$ bond of the protonated $\mathrm{N}^{\varepsilon}$-methyl group. Using multiple HAT reaction path calculations, we demonstrate the crucial role of conformational flexibility in effective hydrogen transfer. Subsequent hydroxylation occurs through a rebound mechanism, which is energetically preferred compared to desaturation, due to second sphere interactions. The overall mechanistic insights reveal the crucial role of iron-center rearrangement, second sphere interactions, and conformational flexibility in PHF8 catalysis and provide knowledge useful for the design of mechanism-based PHF8 inhibitors.

KEYWORDS: histone lysine demethylation, 2-oxoglutarate, non-heme iron enzyme, $Q M / M M$, metal-center rearrangement, enzyme mechanism

\section{INTRODUCTION}

Genetic information in eukaryotic cells is stored in chromatin, which packs DNA and histone proteins in an organized and compact structure. ${ }^{1}$ The basic unit of chromatin, the nucleosome, is usually built from a histone octamer containing two copies each of $\mathrm{H} 2 \mathrm{~A}, \mathrm{H} 2 \mathrm{~B}, \mathrm{H} 3$, and $\mathrm{H} 4$ histones, around which about two turns of DNA are wrapped to form an octamer. ${ }^{1}$ Unstructured $\mathrm{N}$-terminal histone tails extend from the nucleosome and undergo post-translational modifications (PTMs), including methylation, acetylation, and phosphorylation. ${ }^{2,3}$ PTMs of histones affect chromatin structure and function with consequences for compaction, transcription, DNA replication, and DNA damage repair. ${ }^{2,3}$ Histone $N$ - methylation occurs on arginine- and lysine-residues and affects a wide range of biological processes. Misregulation of $\mathrm{N}$ methylation is linked with diseases including cancer. ${ }^{4-6}$ Histone lysines can be mono-, di- and trimethylated (me1, me2, and me 3$){ }^{7}$ changes in methylation status do not significantly change the charge on the $\mathrm{N}^{\varepsilon}$-nitrogen. Depending on its position, lysine $\mathrm{N}^{\varepsilon}$-methylation can be either transcriptionally repressing or activating, e.g., methylation of $\mathrm{K} 9$ or $\mathrm{K} 27$ of histone $\mathrm{H} 3$ can activate transcription, whereas methylation

Received: November 12, 2019

Revised: December 10, 2019

Published: December 11, 2019 
Scheme 1. Proposed Mechanism for the Catalytic Cycle of 2OG Oxygenases Involving either a Ferryl-Flip after the Formation of the "Off-Line" Ferryl-Oxo Intermediate (Path 1) or a Change in the 2OG C-1 Carboxylate Binding Mode from "Off-Line" to "In-Line" Prior to $\mathrm{O}_{2}$ Binding (Path 2)

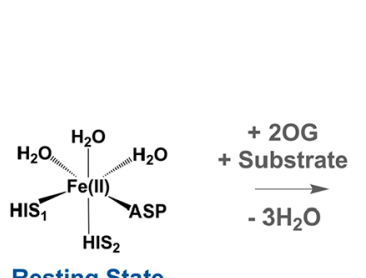

Resting State
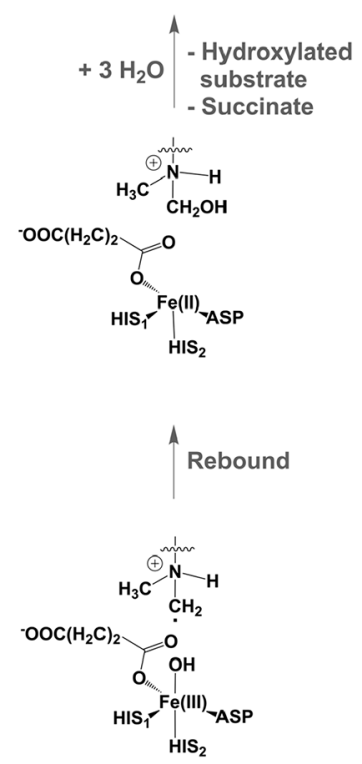

$\uparrow$
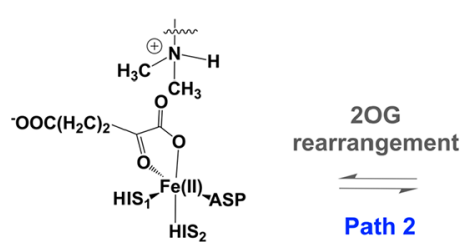

Enzyme Substrate 'off-line'
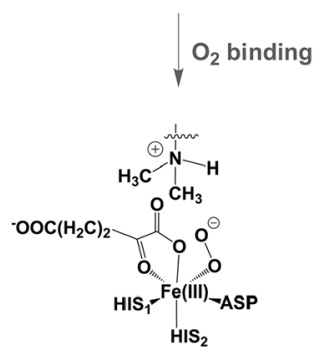

Ferric Superoxo 'off-line'
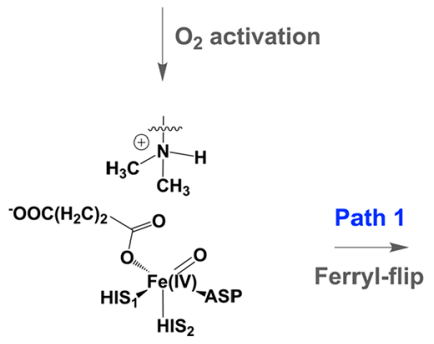

Ferryl Oxo 'off-line'

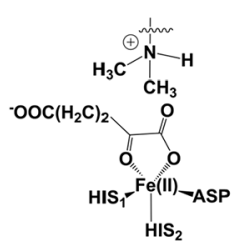

Enzyme Substrate 'in-line'<smiles>C1CCCOCC1</smiles>

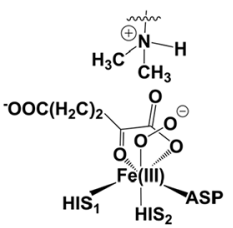

Ferric Superoxo 'in-line'

$\mathrm{O}_{2}$ activation

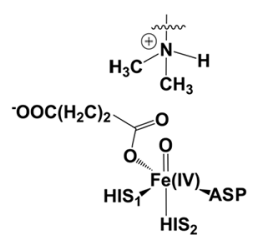

Ferryl Oxo 'in-line'

Hydrogen atom transfer

of $\mathrm{K} 4$ and $\mathrm{K} 36$ of the same histone protein can repress transcription. ${ }^{8}$ Histone methylation was once widely thought to be irreversible, but this view was reversed by the relatively recent identification of histone demethylases (KDMs)., ${ }^{9,10}$

There are two families of histone KDMs: (i) the flavin adenine dinucleotide (FAD)-dependent enzymes (KDM1s) and (ii) the Jumonji $\mathrm{C}(\mathrm{JmjC})$ domain-containing enzymes (KDM2-7 subfamilies in humans). The JmjC proteins are $\mathrm{Fe}$ (II) and 2-oxoglutarate- (2OG-) dependent dioxygenases that couple substrate oxidation to decarboxylation of $2 \mathrm{OG}$ to form succinate, $\mathrm{CO}_{2}$, and a ferryl-oxo intermediate (Scheme 1). The latter performs hydrogen abstraction from the substrate, followed by hydroxylation and nonenzymatic formation of formaldehyde. ${ }^{11,12}$ The catalytic JmjC domain has a conserved distorted double-stranded $\beta$-helix (DSBH) fold, which has a funnel-like structure formed from conserved antiparallel $\beta$ sheets and additional elements, where one end of DSBH harbors the active site including the iron center. ${ }^{13}$ The $2 \mathrm{OG}$ cosubstrate chelates to $\mathrm{Fe}(\mathrm{II})$ via its $\mathrm{C} 1$ carboxylate and $\mathrm{C} 2$ keto groups. ${ }^{11,12}$ Three conserved protein residues (His ${ }_{1}$-XAsp/Glu-X-His 2 triad), present in most $2 \mathrm{OG}$ oxygenases, bind to one face of the octahedrally coordinated metal ion. Most characterized 2OG oxygenases employ a conserved mechanism involving sequential binding of $2 \mathrm{OG}$, substrate, then $\mathrm{O}_{2}{ }^{11,12,14,15}$ 2OG oxygenases play vital roles in the industrial fermentation of vitally important drugs, such as the penicillins and cephalosporins, and drug precursors. ${ }^{8 a}$ Their engineering to directly ferment commercially useful products is of interest. ${ }^{8 a}$ Hence, there is considerable interest in understanding their mechanisms from a biocatalytic perspective.

PHF8 (KDM7B) catalyzes the demethylation of the dimethylated or monomethylated lysine 9 residue in histone $\mathrm{H} 3$ (H3K9me2/me1), in a manner actively promoted by binding of its $\mathrm{N}$-terminal plant homeodomain (PHD) to H3K4me3. ${ }^{16,17}$ The PHF8 gene is overexpressed in many cancers including prostate cancer, ${ }^{18,19}$ breast cancer, ${ }^{20}$ laryngeal cancer, ${ }^{21}$ hypopharyngeal cancer, ${ }^{21}$ nonsmall cell lung cancer, ${ }^{22}$ and esophageal cancer. ${ }^{23}$ Cancer cells in which PHF8 is depleted manifest reduced cell growth ${ }^{19,19,22,23}$ and migration $^{18,23}$ and increased apoptosis. ${ }^{18,19,22}$ Substitution of phenylalanine 279 to serine in PHF8 (F279S) is linked with Xlinked mental retardation. ${ }^{24-27}$ Thus, PHF8 is a current medicinal chemistry target. Crystallographic analysis of PHF8 in complex with a H3K4me3K9me2 fragment ${ }^{16,17}$ informs on interactions between the substrate and the $\mathrm{JmjC}$ and $\mathrm{PHD}$ domains. A PHD-JmjC linker is responsible for the productive orientation of the $\mathrm{JmjC}$ domain to bind $\mathrm{H} 3 \mathrm{~K} 9 \mathrm{me} 2 / \mathrm{me} 1$ productively, as shown by experimental and computational studies. $^{17,28}$

Similarly to other $2 \mathrm{OG}$ dependent hydroxylases, ${ }^{11,12}$ the proposed reaction mechanism for $\mathrm{JmjC} \mathrm{KDMs}$ involves binding of $\mathrm{O}_{2}$ to $\mathrm{Fe}(\mathrm{II}) .2 \mathrm{OG}$.substrate complex. ${ }^{11,12}$ The subsequently formed ferric-superoxo radical complex (Fe(III)- $\mathrm{OO}^{-}$) reacts with $\mathrm{C} 2$ of $2 \mathrm{OG}$, leading to decarboxylation 
and formation of succinate and the ferryl-oxo $(\mathrm{Fe}(\mathrm{IV})=\mathrm{O})$ species (Scheme 1). The reactive ferryl-oxo complex formed can then abstract a hydrogen atom from the lysine $N^{\varepsilon}$-methyl group and form a ferric-hydroxyl species which performs rebound hydroxylation to form a hemiaminal, ${ }^{11,12}$ which, at least in studied cases, rapidly fragments to give formaldehyde and the demethylated lysine-residue. ${ }^{11,12,29}$

Depending on the particular protein environment in $20 \mathrm{G}$ oxygenases, the $2 \mathrm{OG} \mathrm{C} 1$ carboxylate can adopt two different active site $\mathrm{Fe}$-coordination modes. ${ }^{12}$ In one mode, the $2 \mathrm{OG}$ $\mathrm{C} 1$ carboxylate ligates trans to $\mathrm{His}_{1}$, leaving the position trans to $\mathrm{His}_{2}$ for $\mathrm{O}_{2}$ binding (water may need to be displaced). Binding of $\mathrm{O}_{2}$ in this "in-line" mode would lead to the reactive ferryl-oxo intermediate being adjacent to the substrate $\mathrm{C}-\mathrm{H}$ bond (Scheme 1). ${ }^{12,30}$ Evidence for this binding mode comes from crystallographic studies on clavaminate synthase (CAS), ${ }^{30}$ taurine dioxygenase (TauD), ${ }^{31}$ factor inhibiting hypoxia (FIH), ${ }^{32}$ and other $2 \mathrm{OG}$ oxygenases. In the second, "off-line" mode, the 2OG C1 carboxylate binds trans to $\mathrm{His}_{2}$, leaving the position trans to $\mathrm{His}_{1}$ for $\mathrm{O}_{2}$ binding, which is approximately perpendicular to the substrate, as observed in crystallographic studies on carbapenem synthase (CarC), ${ }^{33}$ anthocyanidin synthase (ANS), ${ }^{34}$ alkylated base repair protein (AlkB), ${ }^{35}$ and some other $2 \mathrm{OG}$ oxygenases. Thus, based on the coordination position of the 2OG C1 carboxylate, two possible pathways consistent with crystallographic and kinetic studies have been proposed for the formation of the ferryl-oxo complex $^{30}$ (Scheme 1): (i) The 2OG C1 carboxylate binds trans to $\mathrm{His}_{2}$ in "off-line" binding mode leading to $\mathrm{O}_{2}$ binding trans to $\mathrm{His}_{1}$. In order for the "off-line" mode to produce a catalytically productive ferryl-oxo intermediate, it has been proposed that in some cases the initially formed ferryl intermediate may "flip", potentially via oxygen atom exchange with a solvent water molecule, to a position adjacent to the substrate (path 1, Scheme 1). ${ }^{30}$ Experimental and computational studies for a ferryl-flip via oxygen atom exchange using a water molecule have been reported for natural as well as synthetic non-heme iron enzymes. ${ }^{36-40}$ A ferryl-flip mechanism involving hydration is also consistent with the less than stoichiometric incorporation of an oxygen atom from dioxygen into hydroxylated products in the case of some, but not all, 2OG dependent hydroxylases (by contrast there are consistently high levels of incorporation of single oxygen from dioxygen into succinate). ${ }^{41}$ (ii) Alternatively, in the presence of substrate when the water molecule from the Fe-center is displaced, for $\mathrm{O}_{2}$ binding, the 2OG $\mathrm{Cl}$ carboxylate can rearrange to the position trans to $\mathrm{His}_{1}$ and $\mathrm{O}_{2}$ binds in the position trans to $\mathrm{His}_{2}$. As the $\mathrm{O}_{2}$ binding and subsequent ferryl-oxo intermediate forming are trans to $\mathrm{His}_{2}$, i.e., "in-line" geometry, no ferryl-flip is required, and the mechanism is simpler. ${ }^{30}$ Consistent with the second mechanism, both "inline" and "off-line" binding modes have been observed for PHF8. A PHF $8_{1-447} \cdot \mathrm{Fe}(\mathrm{II}) \cdot \mathrm{H} 3_{1-14} \mathrm{~K} 4 \mathrm{me} 3 \mathrm{~K} 9 \mathrm{me} 2 \cdot \mathrm{NOG}$ (NOG, $N$-oxalylglcyine is a close 2OG analog) crystal structure manifests the NOG C1 carboxylate trans to $\mathrm{His}_{2}$ (His247), i.e. in an "off-line" binding mode, ${ }^{17}$ while a $\mathrm{PHF}_{86-447}$.Fe.2OG crystal structure shows the 2OG C1 carboxylate trans to $\mathrm{His}_{1}$ (His319), i.e., in an "in-line" binding mode. ${ }^{42}$ Also, a crystal structure of PHF8 with a Fe-chelating inhibitor daminozide shows an "in-line" binding mode. ${ }^{43}$

Despite the biophysical insights on PHF8, there is a lack of knowledge on its demethylation mechanism, including with respect to the effects of conformational dynamics on catalysis and the different possible binding modes of 2OG. Alternative mechanistic proposals for the hydrogen abstraction step (HAT), which is often rate-limiting in 2OG oxygenase catalysis, have been proposed based on model compounds; ${ }^{44}$ however, these have not been tested within a protein environment. While the $2 \mathrm{OG}$ iron- $\mathrm{O}_{2}$ derived intermediates (e.g., a superoxo complex) has not been trapped so far, studies with other iron-oxygen intermediates indicate they might have a sufficiently long lifetime to cause conformational changes in proteins. The enzyme ferric-superoxo intermediate has been characterized by crystallographic studies with both non-heme ${ }^{45}$ and heme enzymes, suggesting it has a sufficiently long lifetime to enable conformational changes. ${ }^{46}$ The mean lifetime of a ferryl-oxo intermediate has been measured to be $2.1 \mathrm{~s}$ in another $2 \mathrm{OG}$ dependent oxygenase, $\mathrm{TauD},{ }^{47}$ hence, it is viable to propose it might cause potential conformational changes in the protein. To explore such conformational changes, we performed $1 \mu \mathrm{s}$ molecular dynamics (MD) simulations of PHF8 ferric-superoxo and ferryl-oxo intermediates in PHF8 followed by $\mathrm{QM} / \mathrm{MM}$ reaction path calculations. The results provide insight into the effects of different $20 \mathrm{G}$ binding modes and the role of the protein environment in promoting demethylation performed by PHF8.

\section{METHODS}

System Preparation. A crystal structure of the $\mathrm{PHF} 8_{1-447}$ in complex with $\mathrm{H}_{1-14}$ (Lys4-trimethylated (H3K4me3) and Lys9-dimethylated (H3K9me2)) and the 2OG analog $\mathrm{N}$ oxalylglycine was used for modeling (PDB ID: $3 \mathrm{KV} 4) .{ }^{17}$ Missing residues (1-2, 65-77, including the linker region between the PHD and the JmjC domains) were modeled using Modeler. ${ }^{48}$ The crystal structure manifests Fe-center in "offline" mode bidentate coordination with $2 \mathrm{OG}$ (Scheme 1), and monodentate coordination with two histidines, one aspartic acid, and one water molecule. ${ }^{17}$ To generate parameters for (a) the ferric-superoxo complex, the water molecule coordinated to $\mathrm{Fe}$ in the crystal structure (PDB ID: 3KV4) was replaced with $\mathrm{O}_{2}$ using GaussView 5.0. ${ }^{49}$ The 2OG analog $N$ oxalylglycine was modeled to $2 \mathrm{OG}$ by replacing its $\mathrm{NH}$ with a methylene group using GaussView 5.0. ${ }^{49}$ Hydrogen atoms were added to $2 \mathrm{OG}$ using the leap module of AMBER $16^{50}$ The protonation states of ionizable side chains of the proteins were assessed using Amber routines. ${ }^{51}$ The Amber topology for 2OG, Lys4-trimethylated (H3K4me3), and Lys9-demethylated (H3K9me2) were developed using the GAFF tool in Antechamber. ${ }^{52}$ The Amber parameters for the $\mathrm{Fe}$-superoxo complex active site containing iron (Fe(III) high spin (HS) $S=$ $2, M=5$ ) and the coordinating ligands (2OG, bidentate; $\mathrm{O}_{2}$, bonded in end-on fashion; H247, H319, and D249, all monodentate) were prepared using the Metal Centre Parameter Builder (MCPB) using MCPB.py v3.0. ${ }^{53}$ Bond and angle force constants were derived using the Seminario method, and the point charge parameters for the electrostatic potentials were obtained by RESP charge fitting using the ChgModB method at the B3LYP/6-31G* level of theory. The description of the zinc ion and its coordinating ligands in the PHD domain were described using the Zinc Amber force field (ZAFF) method. ${ }^{54}$ The remainder of the protein was modeled using the Amber FF14SB force field. ${ }^{55}$

The same procedure was used to generate parameters for (b) the ferryl-oxo complex with $\mathrm{H} 3_{1-14} \mathrm{~K} 4 \mathrm{me} 3 \mathrm{~K} 9 \mathrm{me} 2$ histone substrate and succinate. Spectroscopic studies of another $2 \mathrm{OG}$ oxygenase (SyrB2) implies the ferryl-oxo intermediate is a 
five-coordinate complex; ${ }^{56}$ thus, the ferryl-oxo complex of PHF8 (Fe(IV) $=$ O high spin $S=2, M=5$ ) was modeled to be five-coordinate with monodentate succinate, two histidines (H247 and H319), and an aspartate (D249). Previous molecular dynamics simulations run using these parameter generation procedures have successfully reproduced the geometry of non-heme Fe complexes. ${ }^{28,57}$

MD Simulations. The Leap module in AMBER 16 was used to add counterions $\left(\mathrm{Na}^{+}\right)$for the neutralization of the protein systems. The system was immersed into a rectangular box with TIP3Pwater ${ }^{58}$ molecules present up to a minimum of $10 \AA$ from the farthest protein boundary. Periodic boundary conditions were employed in all simulations. Long-range electrostatic interactions were calculated using the particle mesh Ewald (PME) method ${ }^{59}$ with a direct space and vdW cutoff of $10 \AA$.

With a restraint of $100 \mathrm{kcal} \mathrm{mol}^{-1} \AA^{2}$ on solute molecules, the systems were subjected to energy minimization first using the steepest descent (5000 steps) followed by the conjugate gradient (5000 steps). This was followed by the full minimization of the entire system with both steepest descent (5000 steps) and a conjugate gradient (5000 steps) to relax the system. The systems were then subjected to controlled heating from 0 to $300 \mathrm{~K}$ at constant volume using Langevin thermostat $^{60}$ with a collision frequency of $1 \mathrm{ps}^{-1}$ using a canonical ensemble (NVT) MD simulation for 250 ps. The solute molecules were restrained using a harmonic potential of $50 \mathrm{kcal} \mathrm{mol}^{-1} \AA^{2}$ during the heating process. The SHAKE algorithm $^{61}$ was used to constrain bonds involving hydrogen. For ferryl-oxo, an initial MD was performed with harmonic restraint between substrate $\mathrm{H} 3 \mathrm{~K} 9 \mathrm{me} 2$ and the ferryl-oxo for $50 \mathrm{~ns}$. All systems were then equilibrated at $300 \mathrm{~K}$ in an NPT ensemble without restraints for $50 \mathrm{~ns}$; the pressure was maintained at 1 bar using the Berendsen barostat. $^{62}$ A production $\mathrm{MD}$ run from equilibrated structures with explicit solvent for $1 \mu \mathrm{s}$ each with a time step of $2 \mathrm{fs}$ was performed in NPT ensemble with a target pressure set at 1 bar and constant pressure coupling of $2 \mathrm{ps}$. All productive MD simulations were performed with the GPU version of the AMBER 16 package. ${ }^{50}$ Hydrogen bond analysis was done using CPPTRAJ ${ }^{63}$ with a cutoff of $3 \AA$ between donor to the acceptor and $135^{\circ}$ angle between donor-hydrogen-acceptor unless otherwise mentioned. The binding energy values were calculated using MMGBSA method ${ }^{64}$ by taking 10000 frames in account from the respective $1 \mu \mathrm{s}$ MD simulation. Dynamic cross correlation analysis (DCCA) and principal component analysis (PCA) was performed on C- $\alpha$ atoms of PHF8 using trajectory from 500 to 1000 ns with Bio3D. ${ }^{65}$

QM/MM Calculations. Equilibrated structures with productive distance (e.g., distal oxygen and $\mathrm{C} 2$ atom of $2 \mathrm{OG}$ for $\mathrm{O}_{2}$ activation) and an angle (e.g., $\angle \mathrm{Fe}-\mathrm{O}-\mathrm{H}$ for hydrogen atom transfer) were taken from $\mathrm{MD}$ simulations and used for the QM/MM calculations. Excess water molecules were truncated using CPPTRAJ, ${ }^{63}$ such that protein has a water solvation layer of a maximum $12 \AA$ surrounding it. The resulting total size of the systems was $\sim 30000$ atoms. QM/ MM calculations were performed using ChemShell software, ${ }^{66}$ with a combination of Turbomole ${ }^{67}$ for the QM part and DL_POLY ${ }^{68}$ for the MM part. The non-heme Fe center, the first coordinating sphere residues, and substrate-bound in the active site were included in the QM region (Figure 1). An unrestricted B3LYP functional was used to represent the QM region as it has been used for several non-heme ${ }^{69}$ and 2OG-

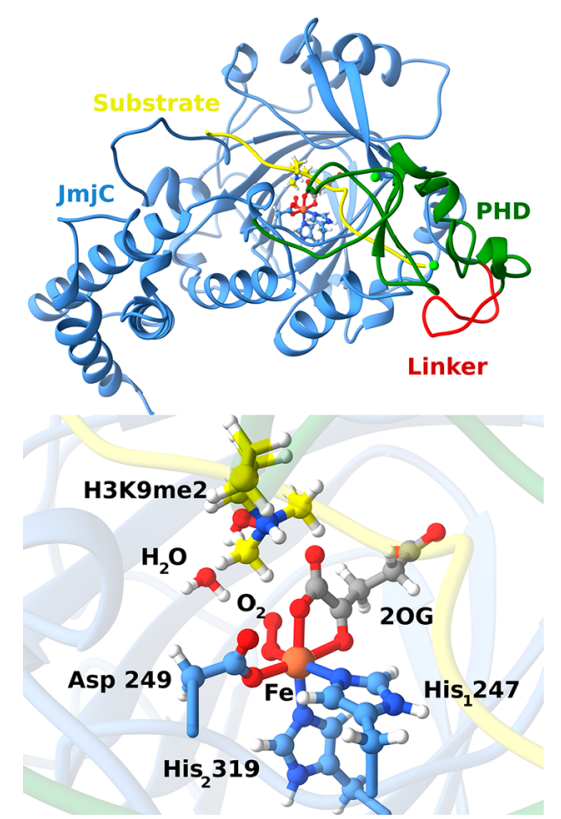

Figure 1. PHF 8 ferric-superoxo intermediate with the $\mathrm{H} 3{ }_{1-14} \mathrm{~K} 4 \mathrm{me} 3 \mathrm{~K} 9 \mathrm{me} 2$ substrate bound at the active site. The QM region used for PHF8 QM/MM calculations is shown in ball and stick format. Note that the 2OG C1 carboxylate is in an "off-line" position in this view (Scheme 1).

enzymes with better accuracy in comparison to other functionals for calculation for hydrogen atom transfer (HAT) barrier. $^{39,70-73}$ The protein region within $8 \AA$ from the QM region was defined as the MM region, and the rest of the system was fixed. The Amber FF14SB force field was used for the $\mathrm{MM}$ region. $\mathrm{QM} / \mathrm{MM}$ boundaries were treated with hydrogen link atom with a charge shift model. ${ }^{74}$ The polarizing effect of the protein environment (MM region) was accounted on the QM region using an electrostatic embedding scheme. ${ }^{75}$ For geometry optimization and frequency calculations, the def2-SVP basis set $[\mathrm{QM}(\mathrm{B} 1) / \mathrm{MM}]$ was $^{\text {used. }}{ }^{76}$

Optimized reactant complexes (RC) were used to search for transition states (TS) along with the reaction coordinate by performing a relaxed potential energy scan (adiabatic mapping $)^{77}$ with a step size of $0.1 \AA$. The highest energy geometry in this potential energy surface (PES) was optimized using the P-RFO optimizer in HDLC code without any constraints. $^{78}$ Frequency calculations of all optimized geometries were carried out to confirm the minima and transitions states. To improve calculated energies, single-point energy calculations on the optimized geometry were done using the large all-electron def2-TZVP basis set $[\mathrm{QM}(\mathrm{B} 2) / \mathrm{MM}] .^{76}$ The zero-point energy (ZPE) calculations were performed for all geometries, and the energies are reported as $\mathrm{QM}(\mathrm{B} 2+\mathrm{ZPE}) /$ MM. The D3 Grimme's dispersion correction ${ }^{79}$ is applied in single-point calculations, and energies are reported as $\mathrm{B} 2+\mathrm{D} 3+\mathrm{ZPE}$ in the Supporting Information. Experimental studies have shown the quintet spin state $(S=2)$ as a ground spin state for studied non-heme enzymes. ${ }^{80-82}$ Several computational studies on $\mathrm{O}_{2}$ activation and HAT pathway in non-heme $20 \mathrm{O}$ dependent enzymes have shown the reaction proceeds through a HS quintet spin state. ${ }^{39,69-72,83,84}$ Therefore, we performed reaction mechanism calculation on the quintet $(S=2, M=5)$ spin state of PHF8 ferric-superoxo and ferryl-oxo complex. The geometries, spin densities, charges, 
A)

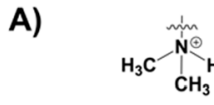

$\stackrel{\mathrm{OOC}\left(\mathrm{H}_{2} \mathrm{C}\right)_{2}}{\mathrm{O}} \mathrm{HIS}_{\text {HIS }}^{\mathrm{Fe}(\mathrm{IV})}$ ASP $+\mathrm{H}_{2} \mathrm{O}$

IM3

$\operatorname{OOC}\left(\mathrm{H}_{2} \mathrm{C}\right)_{2} \overbrace{\text { HIS }}^{\text {Os }}$<smiles>C[N+](C)(C)[Na]</smiles>

$\mathrm{OOC}\left(\mathrm{H}_{2} \mathrm{C}\right)_{2}=\mathrm{O}$

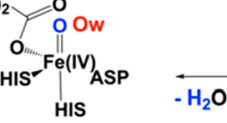

IM8
IM4

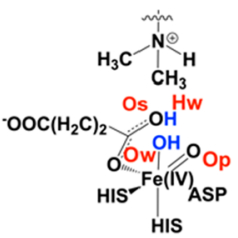

IM5

TS4

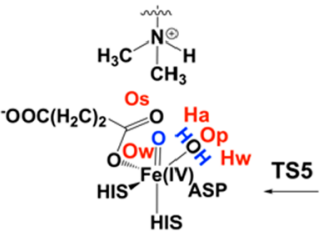

IM7

B)

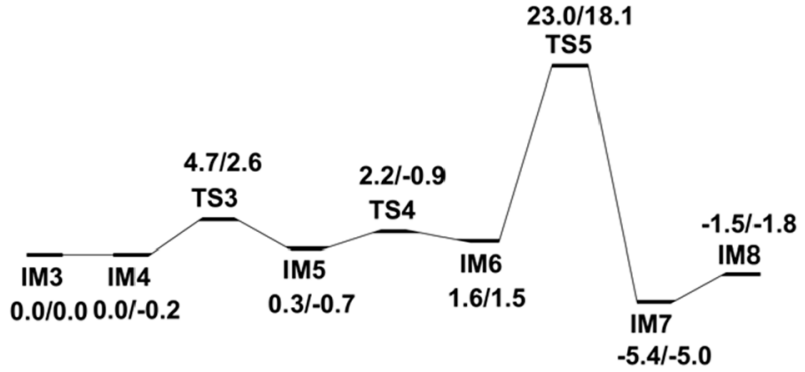

C)
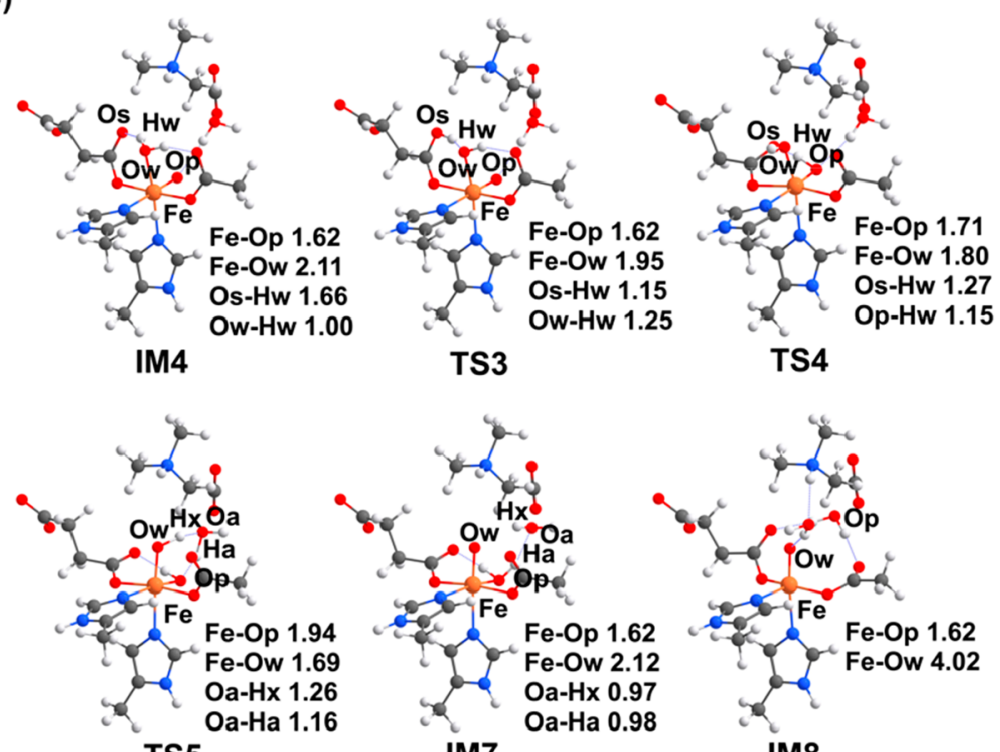

TS5

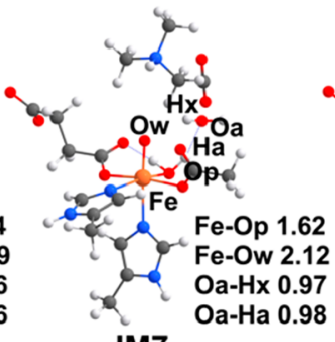

IM7

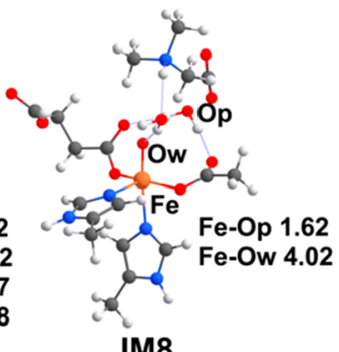

Figure 2. Ferryl-flip mechanism via oxygen atom exchange with a water molecule in PHF8. (A) Proposed mechanistic pathway of a ferryl-flip in an "off-line" PHF8-ferryl-oxo complex. (B) Potential energy surface for the ferryl-flip in the "off-line" PHF8-ferryl-oxo complex. Energies are in kcal/ mol as calculated at $\mathrm{QM}(\mathrm{B} 2) / \mathrm{MM}$ and $\mathrm{QM}(\mathrm{B} 2+\mathrm{ZPE}) / \mathrm{MM}$ level of theory. (C) $\mathrm{QM}$ active site geometries of transition states and selected intermediates in the ferryl-flip mechanism of the "off-line" PHF8-ferryl-oxo complex, from QM/MM calculations. Bond lengths are in angstroms.

and dispersion corrected energies of all intermediates and transition states are presented in Supporting Information.

\section{RESULTS AND DISCUSSION}

3.1. Conformational Flexibility of the Fe(III)-Superoxo Complex. Enzymes are flexible structures that typically exhibit a wide variety of internal motions ranging from femtoseconds to hours, ${ }^{85,86}$ some of which might be relevant to catalysis. ${ }^{87}$ Structural studies imply the ferric-superoxo intermediates in non-heme ${ }^{45}$ and heme ${ }^{46}$ oxygenase catalysis may have sufficiently long lifetimes to enable conformational changes. To investigate whether conformational changes are associated with $\mathrm{O}_{2}$ binding in PHF8 and to obtain equilibrated structures for $\mathrm{QM} / \mathrm{MM}$ calculations, we performed $1 \mu \mathrm{s} \mathrm{MD}$ simulations of the PHF8.Fe(III)-OO- ${ }^{-} \cdot 2 \mathrm{OG}$ (off-line). $\mathrm{H}_{1-14}$ substrate (subsequently referred to as the PHF8-ferricsuperoxo complex). The MD simulations show a well equilibrated PHF8-ferric-superoxo complex with an average 
root mean squared deviation (RMSD) of $1.97 \AA$ for PHF8 C- $\alpha$ atoms with respect to the minimized crystal structure (Figure S1). ${ }^{17}$ Hydrogen bonds with protein residues and the solvent stabilize $20 \mathrm{OG}$ binding, the conformation of the substrate, and the orientation of the Fe-coordinated ligands (Figure S4). The non-Fe coordinating $2 \mathrm{OG}$ C5 carboxylate is stabilized by stable hydrogen bonding with Y257 (present in $80 \%$ of MD snapshots) and K264 (78\%). T253 is positioned to make a hydrogen bond ( $82 \%$ ) with the backbone oxygen of the ironcoordinating aspartic acid (D249). The Fe-coordinating histidines ( $\mathrm{H} 247$ and $\mathrm{H} 319)$ form hydrogen bonds with each other (72\%) and with D245 (76\%) and W317 (15\%), respectively.

Enzymes can exhibit complex correlated motions; dynamic cross correlation analysis (DCCA) can be applied to explore correlated motions in protein dynamics, while principal component analysis (PCA) can be used to analyze motions in flexible regions of proteins. ${ }^{88,89}$ The PHF8-ferric-superoxo complex shows little correlation between motions of the linker and PHD domain with other parts of protein unlike in the PHF8-2OG·H $3_{1-14}$ substrate (enzyme-substrate) complex, ${ }^{28}$ suggesting the significant impact of the dioxygen binding on the network of correlated motions (Figure S5). In comparison with PHF8 enzyme-substrate complex dynamics (Scheme 1 ), ${ }^{28}$ correlated motions are increased in the $\alpha 9$ regions of the JmjC domain in the PHF8-ferric-superoxo complex. The increased motions in the $\alpha 9$ regions of PHF 8 are not manifest in the PHF8 enzyme-substrate complex dynamics ${ }^{28}$ and hence appear related to $\mathrm{O}_{2}$ binding. Principal component analysis (PCA) reveals that the $\alpha 9$ regions move toward the active site, apparently preparing the complex for catalysis (Figure S6).

3.2. $\mathrm{O}_{2}$ Activation Mechanism from "Off-Line" and "In-Line" 20G Binding Modes. The reaction mechanism for the oxygen activation mechanism in PHF8.Fe(III)$\mathrm{OO}^{-} .2 \mathrm{OG} . \mathrm{H} 3_{1-14}$ substrate starting from both "off-line" RC1, or "in-line" $\mathbf{R C 1}$ ' binding mode of $2 \mathrm{OG}$ was studied using $\mathrm{QM} / \mathrm{MM}$ calculations. The intermediates and transition states obtained for both the "in-line" and "off-line" $20 \mathrm{OG}$ binding mode in PHF8 are similar to those identified for other 2OG dependent enzymes (Figures S7-S13). ${ }^{39,69-72,83,90-92}$ The mechanism proceeds via attack of the distal oxygen $(\mathrm{Od})$ onto $\mathrm{C} 2$ of $2 \mathrm{OG}$, leading to a loss of $\mathrm{CO}_{2}$ to form a decarboxylated succinyl-peroxide intermediate IM1/IM1', which has been recently characterized crystallographically for a $2 \mathrm{OG}$ dependent enzyme VioC. ${ }^{90}$ The energy barrier for decarboxylation, which is the rate-determining step in the $\mathrm{O}_{2}$ activation process, is 12.7 and $10.2 \mathrm{kcal} / \mathrm{mol}$ at the $\mathrm{QM}(\mathrm{B} 2+\mathrm{ZPE}) / \mathrm{MM}$ level of theory for "off-line" and "inline" modes of 2OG, and slightly favors "in-line" binding of $2 \mathrm{OG}$ for $\mathrm{O}_{2}$ activation (Figure S7 - S8). These energy barriers compare reasonably well to experimental kinetic data on $\mathrm{TauD}$, a similar $2 \mathrm{OG}$ dependent enzyme $(15.2 \mathrm{kcal} / \mathrm{mol}$, calculated from rate constant value of $\left.42 \mathrm{~s}^{-1}\right)^{93}$ and computational studies on other $2 \mathrm{OG}$ oxygenases. ${ }^{70-72}$ The succinyl-peroxide IM1/IM1' then undergoes homolytic cleavage of the $\mathrm{O}-\mathrm{O}$ bond to generate a ferryl-oxo intermediate IM3/IM3'. The ferryl-oxo formed from "off-line" binding mode of 2OG IM3 has the oxo group trans to His247, i.e., away from the substrate (Figure S7) while the ferryl-oxo formed from "in-line" binding mode of 2OG IM3' has the oxo group trans to His319, i.e. close to substrate (Figure S13). The geometries and spin densities of all intermediates and transition state in the $\mathrm{O}_{2}$ activation mechanism are shown in Supporting Information (Table S1 and S7) and are consistent with computational studies on similar 2OG enzymes. ${ }^{39,69-72,83,90}$

3.3. The Ferryl-Flip Mechanism via Solvent Oxygen Atom Exchange. The "off-line" ferryl-oxo intermediate (IM3) generated after $\mathrm{O}_{2}$ activation has to be oriented in the direction of the substrate for productive catalysis, i.e., adopt an "in-line" geometry. One possible mechanism for such reorientation is via oxygen atom exchange with a water molecule (Figure $2 \mathrm{~A}){ }^{12,30}$ This process could begin by binding of a water molecule to the open coordination site of the $\mathrm{Fe}$ center at the IM3 intermediate stage (Figure 2B). The so formed intermediate (IM4) is a six-coordinate "off-line" ferryl-oxo with a water molecule facing in the direction of the substrate (Figure 2C). The bond length between $\mathrm{Fe}$ and the oxygen of water $(\mathrm{Ow})$ is $2.11 \AA$; the Fe-Op bond distance is the same as in IM3 (i.e., $1.62 \AA$ ) and agrees well with another computational study of oxygen atom exchange in a $2 \mathrm{OG}$ oxygenase (AsqJ). ${ }^{39}$ The proton $(\mathrm{Hw})$ of the $\mathrm{Fe}$ coordinated water is transferred to the succinate oxygen (Os label on Figure $2 \mathrm{~A} / 2 \mathrm{C}$ ) to form an intermediate (IM5) with a low barrier of $2.6 \mathrm{kcal} / \mathrm{mol}$ at $\mathrm{QM}(\mathrm{B} 2+\mathrm{ZPE}) / \mathrm{MM}$ level of theory via a transition state (TS3). IM5 then rearranges to give the ferryl-dihydroxyl species IM6 with a very low energy barrier (of 1.9 at $\mathrm{B} 2$ and $-0.2 \mathrm{kcal} / \mathrm{mol}$ at $\mathrm{QM}(\mathrm{B} 2+\mathrm{ZPE}) /$ $\mathrm{MM}$ ). In IM6, the $\mathrm{Fe}-\mathrm{Op}$ and $\mathrm{Fe}-\mathrm{Ow}$ bond distances are 1.73 and $1.79 \AA$, respectively, which compares well with a computational study on AsqJ. ${ }^{39}$ To complete the ferryl-flip, the second proton of the ligating water molecule $(\mathrm{Hx})$ is transferred to Op via a proton-relay transfer with the help of a nearby water molecule. The second proton transfer proceeds with a transition state (TS5), which is $16.6 \mathrm{kcal} / \mathrm{mol}$ higher in energy than the previous intermediate at the $\mathrm{QM}(\mathrm{B} 2+\mathrm{ZPE}) /$ MM level of theory. The intermediate (IM7) formed is the flipped six-coordinated "in-line" complex. This intermediate (IM7) can then release a water molecule and give a final flipped "in-line" 5-coordinate ferryl-oxo complex (IM8). Although the flipped 5-coordinate complex (IM8) is slightly higher in energy (by $3.2 \mathrm{kcal} / \mathrm{mol}$ ) than the 6-coordinate "inline" ferryl-oxo, modeling studies show that ferryl-oxo species can be either five- or six-coordinate; ${ }^{94-96}$ spectroscopic studies with another 2OG oxygenase (SyrB2) imply the ferryloxo is five-coordinate. ${ }^{56}$ The total barrier for the ferryl-flip via oxygen atom exchange is calculated to be $18.1 \mathrm{kcal} / \mathrm{mol}$ at the $\mathrm{QM}(\mathrm{B} 2+\mathrm{ZPE}) / \mathrm{MM}$ level of theory, which is higher than a previously reported barrier of $10.9 \mathrm{kcal} / \mathrm{mol}$ for the $2 \mathrm{OG}$ oxygenase Asqj. ${ }^{39}$ The higher reaction barrier for the ferryl-flip in the case of PHF8 might be due to its more compact active site, ${ }^{17,44}$ and the steric hindrance between the water molecule needed for proton-relay in TS5 and the methyl groups of the substrate, which is not the case in AsqJ. Since the total barrier for the ferryl-flip is relatively high in PHF8, it may not be an energetically favored pathway for formation of the "in-line" ferryl-oxo intermediate, but it cannot be completely excluded as the barrier is still less than the experimental barrier of 21.3 $\mathrm{kcal} / \mathrm{mol}$ (calculated from a rate constant of $5.4 \mathrm{~h}^{-1}$ ) for the hydrogen abstraction step of PHF8, which is believed to be the rate-determining step in the entire reaction mechanism of PHF8. ${ }^{17}$

3.4. 2OG Rearrangement before $\mathrm{O}_{2}$ Binding. To explore the change in the binding mode of $2 \mathrm{OG}$ from "offline" to "in-line" in PHF8, we calculated a potential energy surface by changing the dihedral angle for $\mathrm{N}^{\varepsilon}$ (nitrogen of 
$\left.\mathrm{His}_{1}\right)-\mathrm{Fe}-\mathrm{O} 2-\mathrm{O} 1$. We first optimized the five-coordinate PHF8 enzyme-substrate complex at the QM/MM level. The five-coordinate PHF8 enzyme-substrate complex (ES1) has iron in the $\mathrm{Fe}$ (II) high spin $S=2, M=5$ state, with the $2 \mathrm{OG}$ bound in an "off-line" bidentate fashion, and two histidines (H247 and H319) and an aspartate (D249) bound in monodentate fashion along with the $\mathrm{H} 3{ }_{1-14} \mathrm{~K} 4 \mathrm{me} 3 \mathrm{~K} 9 \mathrm{me} 2$ substrate. The bond lengths of iron and the two coordinating oxygens of $2 \mathrm{OG}(\mathrm{Fe}-\mathrm{O} 1$ and $\mathrm{Fe}-\mathrm{O} 2)$ are increased from 1.97 and $2.31 \AA$ in RC1 to 2.03 and $2.48 \AA$, respectively, in ES1 (Figure 3 ). The dihedral angle for $\mathrm{N}^{\varepsilon}$ (nitrogen of $\mathrm{His}_{1}$ )-Fe-
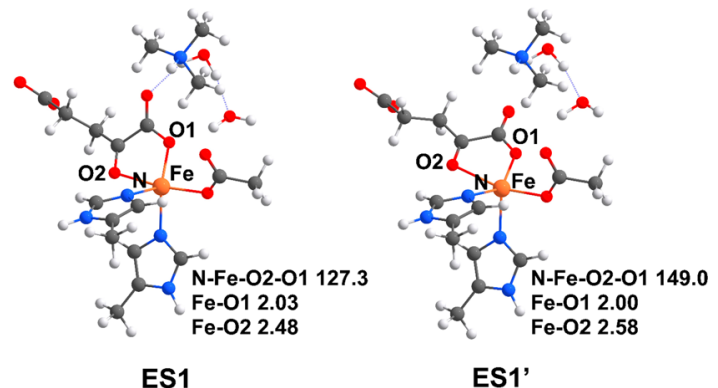

Figure 3. QM region geometry of QM/MM optimized ES1 and ES1' for calculations involving a change in the binding mode of 2OG from "off-line" in ES1 to "in-line" in ES1'. Angles and bond lengths are in degrees and angstroms, respectively.

$\mathrm{O} 2-\mathrm{O} 1$ also changes from $100^{\circ}$ in $\mathrm{RC} 1$ to $127^{\circ}$ in ES1. The potential energy surface was calculated starting from ES1, using a reaction coordinate of the dihedral angle $\mathrm{N}^{\varepsilon}$ (nitrogen of $\left.\mathrm{His}_{1}\right)-\mathrm{Fe}-\mathrm{O} 2-\mathrm{O} 1$ to give the "in-line" five-coordinate enzyme-substrate complex ES1' (Figure 3). The dihedral rotation which leads to the "in-line" five-coordinate PHF8 enzyme-substrate complex (ES1') proceeds with a low barrier of $1.48 \mathrm{kcal} / \mathrm{mol}$ (at the $\mathrm{QM}(\mathrm{B} 2+\mathrm{ZPE}) / \mathrm{MM}$ level of theory) principally because there are no protein residues interacting with the $\mathrm{C} 1$ carboxylate of $2 \mathrm{OG}$ in ES1. The transition state (ES2) has a dihedral angle of $144^{\circ}$ for $\mathrm{N}^{\varepsilon}$ (nitrogen of $\mathrm{His}_{1}$ )$\mathrm{Fe}-\mathrm{O} 2-\mathrm{O} 1$, and bond lengths between iron and the two coordinating oxygens of $2 \mathrm{OG}(\mathrm{Fe}-\mathrm{O} 1$ and $\mathrm{Fe}-\mathrm{O} 2)$ of 2.02 and $2.52 \AA$, respectively. The "in-line" five-coordinate PHF8 enzyme-substrate complex $\left(\mathbf{E S 1}^{\prime}\right)$ has a relative energy of $-0.98 \mathrm{kcal} / \mathrm{mol}$ with respect to $\mathrm{ES} 1$ at the $\mathrm{QM}(\mathrm{B} 2+\mathrm{ZPE}) /$ MM level of theory. The dihedral angle for N(nitrogen of $\left.\mathrm{His}_{1}\right)-\mathrm{Fe}-\mathrm{O} 2-\mathrm{O} 1$ in $\mathbf{E S 1}^{\prime}$ increases to $149^{\circ}$, with bond lengths between iron and the two coordinating oxygens of $2 \mathrm{OG}(\mathrm{Fe}-\mathrm{O} 1$ and $\mathrm{Fe}-\mathrm{O} 2)$ of 2.0 and $2.6 \AA$, respectively.

Thus, the change from "off-line" to "in-line" coordination mode of $2 \mathrm{OG}$ in PHF8 proceeds with a relatively low barrier, suggesting both possible 2OG C1 carboxylate geometries might coexist at room temperature. Consistent with the result of a change in the binding mode of 2OG in PHF8, the CAS.Fe(II).2OG.substrate.NO crystal structure (NO is used as an analog for $\mathrm{O}_{2}$ ) shows a changed binding mode in the 2OG $\mathrm{C} 1$ carboxylate geometry upon NO binding in comparison to the CAS.Fe(II).2OG.substrate crystal structure. ${ }^{30}$ Crystal structures of KDM2A.Ni·H3K36me1-3.2OG/NOG (Ni and NOG are used as analogs for Fe and 2OG, respectively) show evidence for both "in-line" and "off-line" binding modes of the 2OG/NOG C1 carboxylate, but the KDM2A.Fe.H3K36me1.succinate.NO structure (note the 2OG in the crystal structure was reported to be oxidized to succinate even though the
H3K36 substrate remained methylated) was refined to show only the "in-line" binding mode; i.e., NO was bound trans to $\mathrm{His}_{2}{ }^{97}$

3.5. Conformational Dynamics and Substrate Stabilization in PHF8 $\mathrm{Fe}(\mathrm{IV})=0$ Intermediate. The ferryl-oxo species is a key intermediate in $20 \mathrm{OG}$ oxygenase catalysis that performs hydrogen abstraction from the substrate. This process might be sensitive to the dynamic orientation between the substrate and the iron, which is likely controlled by conformational changes. ${ }^{98-100}$ The mean lifetime of a ferryloxo intermediate has been measured to be $2.1 \mathrm{~s}$ for the $2 \mathrm{OG}$ dependent $\mathrm{TauD},{ }^{47}$ and hence appears stable enough to enable potential conformational changes. To explore this possibility, we performed $1 \mu \mathrm{s}$ MD simulations of the PHF8-ferryl-oxoinline complex (IM8) with succinate and the $\mathrm{H} 3_{1-14} \mathrm{~K} 4 \mathrm{me} 3 \mathrm{~K} 9 \mathrm{me} 2$ histone substrate. The MD simulations indicate a well equilibrated PHF8-ferryl-oxo-inline complex with an average root mean squared deviation of $2.03 \AA$ for $\mathrm{C}$ - $\alpha$ atoms of the protein from the $\mathrm{QM} / \mathrm{MM}$ optimized starting structure IM8 (Figure S15). The protein stabilizes the $\mathrm{H} 3 \mathrm{~K} 9 \mathrm{me} 2$ substrate and the iron center via multiple hydrogen bonds (Figure S18). The noncoordinating (C4) carboxyl group of succinate is stabilized by hydrogen bonding interactions with Y257 (83\%), N189 (61\%), K264 (60\%), and T244 (41\%), and solvent-mediated hydrogen bonds with the iron-ligated D249 (50\%) and T253 (52\%). The H3K9me2 is supported by hydrogen bonding with F250 (72\%), R460 (70\%), and a steric interaction with I191. T253 (75\%) and G252 (12\%) make hydrogen bonds to support the backbone oxygen of the Fe-coordinating D249, while the noncoordinating oxygen of the D249 carboxyl group makes a strong interaction with N333. The coordinating histidines (H247, H319) form a hydrogen bond with each other (89\%) and with residues D245 (70\%) and $\mathrm{W} 317$ (28\%), respectively.

After $300 \mathrm{~ns}$, the $\mathrm{H} 3 \mathrm{~K} 9 \mathrm{me} 2$ substrate equilibrates to a conformation wherein one of the substrate methyl groups is closest to the ferryl-oxo unit, followed by another methyl group and hydrogen of $\mathrm{NH}$ (Figure 4). These observations suggest that the first hydrogen abstraction happens from the methyl group of the substrate. Similarly to observations with

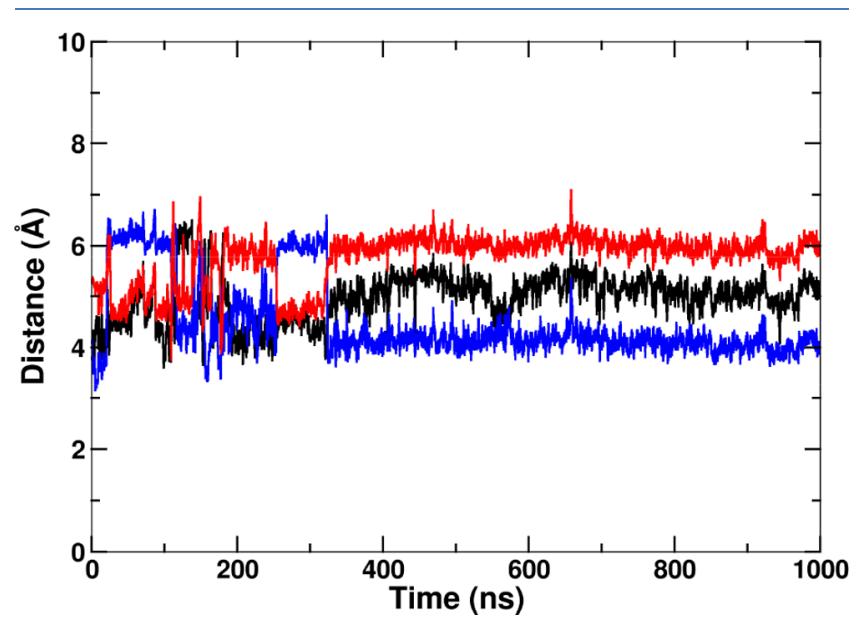

Figure 4. Distance between the ferryl-oxo oxygen atom and carbon atom of the first methyl group (black), carbon atom of the second methyl group (blue), and hydrogen of the amino group (red) of $\mathrm{H} 3 \mathrm{~K} 9 \mathrm{me} 2$ substrate in the dynamics of PHF8-ferryl-oxo-inline complex. 
A)

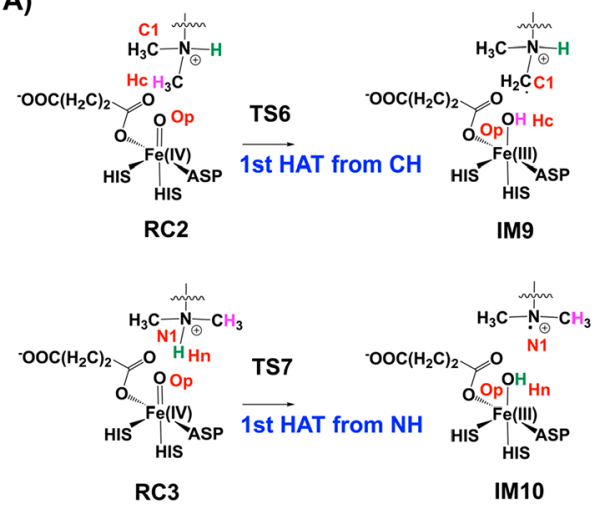

B)

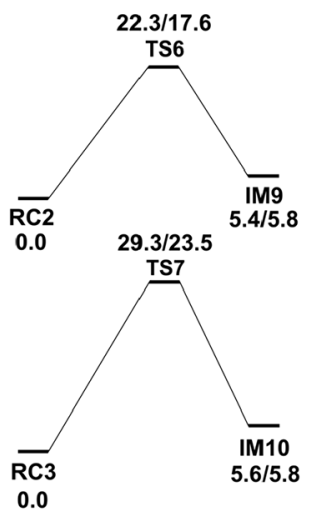

C)

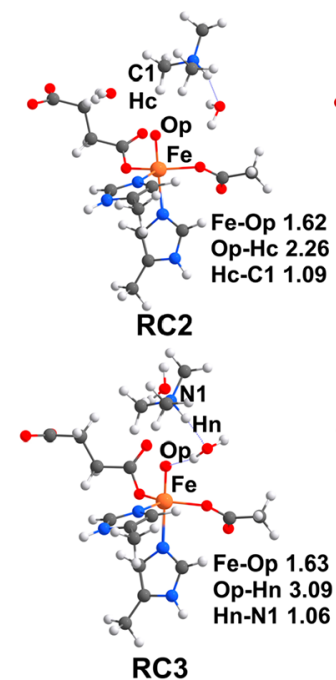

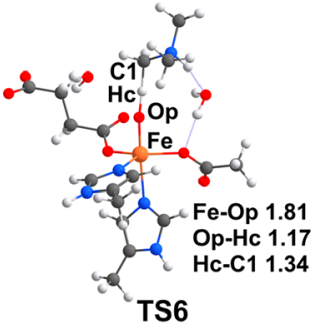

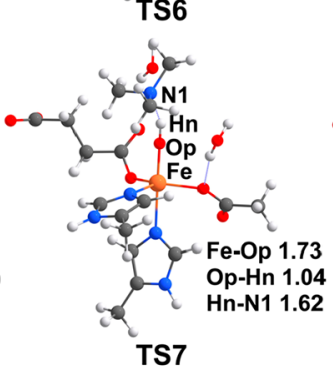

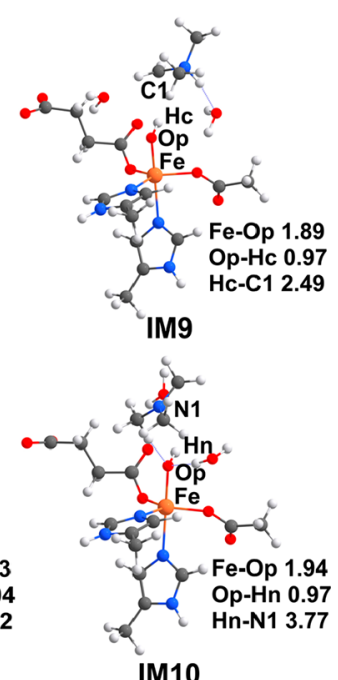

Figure 5. (A) Possible first hydrogen abstraction pathways from CH (RC3-TS6-IM9) and NH (RC4-TS7-IM10). (B) Potential energy surface for hydrogen abstraction step for hydrogen abstraction from carbon $(\mathrm{CH})$ and for hydrogen abstraction from nitrogen $(\mathrm{NH})$. Energies are reported in $\mathrm{kcal} / \mathrm{mol}$ as calculated at the $\mathrm{QM}(\mathrm{B} 2) / \mathrm{MM}$ and $\mathrm{QM}(\mathrm{B} 2+\mathrm{ZPE}) / \mathrm{MM}$ level of theory. (C) $\mathrm{QM}$ active site geometries of transition states and selected intermediates in the hydrogen atom transfer mechanism of PHF8 from QM/MM calculations. Bond lengths are in angstroms.

the PHF8-ferric-superoxo MD simulations, the PHD domain and the linker show reduced correlated motions, which could provide a stable enzyme conformation for catalysis (Figure S19). The motions in $\alpha 9-\alpha 12$ are increased in comparison with the PHF8-ferric-superoxo $\mathrm{MD}$ and show motion in the direction of the active site, thus further compressing the overall PHF8 conformation (Figure S20). Such conformational changes will improve binding between PHF8 and the substrate, as seen in the calculated binding energies of the PHF8.Fe(IV). oxo-succinate $\cdot \mathrm{H} 3_{1-14} \mathrm{~K} 4 \mathrm{me} 3 \mathrm{~K} 9 \mathrm{me} 2$ complex $(-139.0 \mathrm{kcal} /$ $\mathrm{mol})$ and PHF8.Fe(III)-superoxo-2OG.H3 ${ }_{1-14} \mathrm{~K} 4 \mathrm{me} 3 \mathrm{~K} 9 \mathrm{me} 2$ complex $(-80.6 \mathrm{kcal} / \mathrm{mol})$.

3.6. Hydrogen Atom Abstraction (HAT) Takes Place from $\mathbf{C}-\mathrm{H}$ Rather Than $\mathbf{N}-\mathrm{H}$. It is generally accepted that in non-heme enzyme catalyzed demethylation, the oxygen atom of the $\mathrm{Fe}(\mathrm{IV})=\mathrm{O}$ species abstracts a hydrogen atom from the methyl group of the substrate to form a $\mathrm{Fe}(\mathrm{III})-\mathrm{OH}$ group and a substrate-based radical. ${ }^{11,12}$ For PHF8, since the H3K9 substrate is dimethylated, the $\mathrm{Fe}(\mathrm{IV})=\mathrm{O}$ could also (potentially) attack a hydrogen atom on the $\mathrm{N}$ atom of H3K9me2 substrate. It has further been proposed that hydrogen atom abstraction can occur either from the methyl group or from the $\mathrm{NH}$ group, depending on the orientation of H3K9me2 with respect to the $\mathrm{Fe}-\mathrm{O}$ bond (Figure 5A). ${ }^{44}$
When the hydrogen atom of the $\mathrm{NH}$ group of the substrate points away from the iron-center, it is denoted as an "H-out" conformation (shown as reactant RC2 in Figure 5C), and if the hydrogen atom of the $\mathrm{NH}$ group points toward the ironcenter, it has been denoted as an "H-in" conformation (shown as reactant RC3 in Figure 5C). Previous QM calculations on non-heme models of methylated lysine have indicated that for the dimethylated substrate, hydrogen abstraction from a methyl group and $\mathrm{NH}$ group are both feasible. ${ }^{44}$ The MD simulations of the ferryl-oxo complex in PHF8 show the $\mathrm{NH}$ group in the "H-out" conformation, which makes $\mathrm{NH}$ abstraction less energetically favorable than $\mathrm{C}-\mathrm{H}$ abstraction (Figure 4). To verify further the MD prediction of the ferryloxo PHF8 structure, we carried out a QM/MM potential energy surface for both $\mathrm{C}-\mathrm{H}$ and $\mathrm{N}-\mathrm{H}$ abstraction steps.

Two snapshots from PHF8-ferryl-oxo MD were chosen for $\mathrm{QM} / \mathrm{MM}$ analysis, one snapshot with the "H-out" conformation which is apparently favorable for $\mathrm{C}-\mathrm{H}$ abstraction (RC2), and another snapshot with " $\mathrm{H}$-in" conformation, which is apparently favorable for $\mathrm{N}-\mathrm{H}$ abstraction (RC3) (Figure 5C). The starting MD snapshots of reactants, RC2 and RC3, have the ferryl-oxo at distances of 2.3 and $2.6 \AA$ from the hydrogen atom of carbon and nitrogen $(\mathrm{O}-\mathrm{HC} / \mathrm{O}-\mathrm{HN})$, respectively; the $\mathrm{Fe}-\mathrm{O}-\mathrm{HC} / \mathrm{Fe}-\mathrm{O}-\mathrm{HN}$ angles are $163^{\circ}$ and $139^{\circ}$, 
Table 1. Table Showing the $\angle \mathrm{Fe}-\mathrm{O}-\mathrm{H}$ Angles for QM/MM Optimized Multiple Snapshots of the First $\mathrm{C}-\mathrm{H}$ Abstraction Step, with Spin Densities on the Methyl Carbon Atom $\left(\sigma_{\mathrm{CH}}\right)$ of the Substrate and Energy Barriers for the Transfer Listed

\begin{tabular}{|c|c|c|c|c|}
\hline \multirow[b]{2}{*}{ snapshot number } & \multirow[b]{2}{*}{ energy barrier $[\mathrm{QM}(\mathrm{B} 2+\mathrm{ZPE}) / \mathrm{MM}]$} & \multicolumn{2}{|c|}{$\angle \mathrm{Fe}-\mathrm{O}-\mathrm{H}$} & \multirow[b]{2}{*}{ spin density on C-atom in TS } \\
\hline & & QM/MM optimized $\mathbf{R C}$ & QM/MM optimized TS & \\
\hline 1 & 24.57 & 163 & 164 & -0.50 \\
\hline 2 & 21.43 & 154 & 142 & -0.47 \\
\hline 3 & 17.65 & 167 & 150 & -0.49 \\
\hline 4 & 21.48 & 144 & 152 & -0.51 \\
\hline 5 & 17.64 & 127 & 164 & -0.53 \\
\hline
\end{tabular}

respectively. QM/MM optimization of both snapshots changes the $\mathrm{O}-\mathrm{HC} / \mathrm{O}-\mathrm{NH}$ distances to $2.2 / 3.1 \AA$ and $\mathrm{Fe}-\mathrm{O}-\mathrm{HC} /$ $\mathrm{Fe}-\mathrm{O}-\mathrm{HN}$ angles to $167^{\circ} / 149^{\circ}$, respectively, for RC2/RC3. The potential energy surfaces for hydrogen atom transfer from RC2 and RC3 are shown in Figure 5B. The activation barriers of the two HAT reactions with RC2 and RC3 are 17.6 and $23.5 \mathrm{kcal} / \mathrm{mol}$, respectively, at the $\mathrm{QM}(\mathrm{B} 2+\mathrm{ZPE}) / \mathrm{MM}$ level of theory, suggesting that HAT involving $\mathrm{C}-\mathrm{H}$ abstraction is the more energetically preferable reaction. The D3 dispersion corrected energies also reproduce the same trend and are shown in Supporting Information with spin densities (Table S9). The QM/MM calculations support the proposal of unfavorable $\mathrm{N}-\mathrm{H}$ abstraction on the basis of $\mathrm{MD}$ studies. Thus, the substrate conformation and the protein environment around the active site of PHF8 support $\mathrm{H}$-abstraction from the methyl group of the substrate to form a ferric-hydroxyl species and a substrate-based radical.

3.7. Conformational Flexibility, Molecular Orbitals, and Six-Coordinated $\mathrm{Fe}(\mathrm{IV})=0$ in the Hydrogen Atom Transfer. We performed multiple reaction path calculations starting from different structures of the ferryl-oxo complex generated by $\mathrm{MD}$ to explore the effects of conformational flexibility on the HAT. In all the HAT transition states, the iron-center is stabilized by a chain of hydrogen bonding water molecules. The orientation of the $\mathrm{H} 3 \mathrm{~K} 9 \mathrm{me} 2$ substrate toward the ferryl-oxo is maintained by interactions from I191 and H3R8. The nonbonded oxygen of Fe-coordinated Asp249 makes hydrogen with N333. The Boltzmann-averaged reaction barrier for the rate-determining first hydrogen abstraction step using five snapshots was found to be $18.19 \mathrm{kcal} / \mathrm{mol}$ at $\mathrm{QM}(\mathrm{B} 2+\mathrm{ZPE}) / \mathrm{MM}$ level of theory (Table 1) and compares reasonably well with the experimental barrier of $21.3 \mathrm{kcal} / \mathrm{mol}$ (calculated from a rate constant of $\left.5.4 \mathrm{~h}^{-1}\right)^{17}$ and other computational studies on similar $2 \mathrm{OG}$ oxygenases. ${ }^{95,96,101,102}$

The ferryl-oxo complex RC2 is considered "in-line", as its $\mathrm{Fe}=\mathrm{O}$ bond is oriented along the direction of the substrate (taken as the $z$-axis). ${ }^{98,99}$ In the quintet spin state of RC2, the Fe $3 \mathrm{~d}$ orbitals are split into two $\pi^{*}$ orbitals $\left(\pi^{*}{ }_{x z}\right.$ and $\left.\pi^{*}{ }_{y z}\right)$, two $\sigma^{*}\left(\sigma_{x^{2}-y^{2}}\right.$ and $\left.\sigma_{z}^{*}{ }_{z}^{2}\right)$ orbitals, and a nonbonding $\left(\delta_{x y}\right)$ orbital. The antibonding interactions between the $3 \mathrm{~d}$ orbitals of $\mathrm{Fe}$ and the $2 \mathrm{p}$ orbitals of the oxo ligand result in the $\pi^{*}{ }_{x z}$ and $\pi^{*}{ }_{y z}$ orbitals, instead of $\pi^{*}{ }_{x y}$ and $\pi^{*}{ }_{y z}$, as in IM3 (Figure S14). The $\sigma_{z}^{*}$ in RC2 is the result of an antibonding interaction between the $3 \mathrm{~d}_{z}{ }^{2}$ orbital of the $\mathrm{Fe}$ and the $2 \mathrm{p}_{z}$ orbital of the oxo group; the $\sigma_{x-y}^{* 2}{ }^{2}$ orbital arises from an antibonding interaction between $3 \mathrm{~d}_{x^{2}-y^{2}}$ of $\mathrm{Fe}$ and ligands in the $x-y$ plane (H247, D249, and succinate). Therefore, the orbital occupancy of quintet RC2 is $\delta_{x y}{ }^{1} \pi^{*}{ }_{x z}{ }^{1} \pi^{*}{ }_{y z}{ }^{1} \sigma^{*}{ }_{x}{ }^{2}-y^{2}{ }^{1} \sigma^{*} z^{2^{0}}$. The orbital arrangement in RC2 leads to a stabilization of $\alpha$ spin orbitals via an exchange enhanced reactivity, which lowers the energy of the $\alpha-\sigma_{z^{2}}^{*}$ orbital. $^{98,99,103,104}$ Thus, there are two types of frontier molecular orbitals (FMOs), the $\sigma_{z^{2}}^{*}$ and the degenerate $\pi_{x z / y z}^{*}$ available for hydrogen atom abstraction. ${ }^{98,99}$ In the RC2, the $\sigma_{z}^{*}$ orbital lies along the direction of the ferryl-oxo bond, while the $\pi^{*}$ orbitals lie perpendicular to the direction of the $\mathrm{Fe}-\mathrm{O}$ vector.

For the transition states of hydrogen transfer, the orbital overlap is optimized by a $\mathrm{Fe}-\mathrm{O}-\mathrm{H}$ angle close to $180^{\circ}$ for $\sigma^{*}$ electron transfer and a $\mathrm{Fe}-\mathrm{O}-\mathrm{H}$ angle close to $120^{\circ}$ for $\pi^{*}$ electron transfer (Figure 6). ${ }^{98,99}$ Several calculated transition states of HAT reactions by $\mathrm{Fe}(\mathrm{IV})=\mathrm{O}$ species have shown to follow these orbital-selection rules. ${ }^{98-100}$

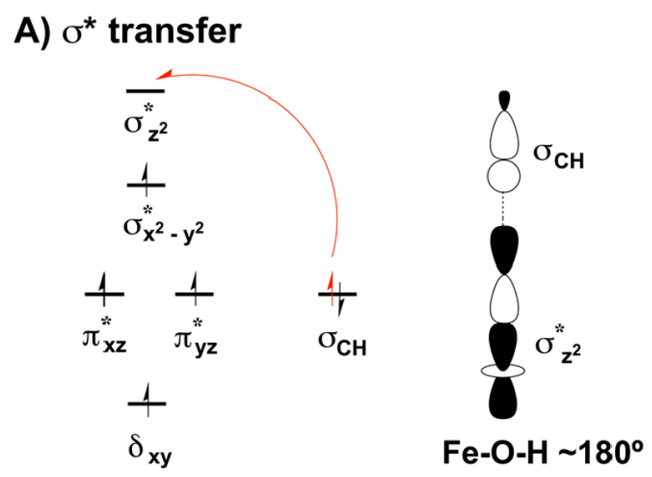

B) $\pi^{*}$ transfer

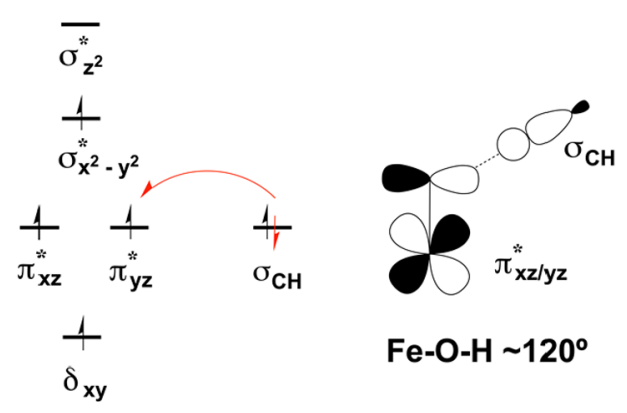

Figure 6. Orbital selection rules for the hydrogen abstraction process in high-spin $(S=2)$ non-heme iron-oxo intermediates.

To investigate how electron transfer in PHF8 occurs, we analyzed transition state geometries from the five QM/MM snapshots for the HAT from the $\mathrm{C}-\mathrm{H}$ bond. The $\angle \mathrm{Fe}-\mathrm{O}-\mathrm{H}$ in the transition state of all the five reaction paths remains in the range of $142^{\circ}-164^{\circ}$, implying electron transfer via the $\sigma^{*}$ pathway. In $\mathrm{PHF} 8$, a transition state $\angle \mathrm{Fe}-\mathrm{O}-\mathrm{H}$ close to $180^{\circ}$ is favored due to an interaction between the I191 side chain and the methyl groups of the substrate. The spin natural orbital (SNO) of the HAT transition state (TS6) shows electron transfer to the ferryl-oxo $\sigma_{z}^{*}$ orbital (Figure 7). $\sigma^{*}-\alpha$ electron transfer is supported by the residual negative spin density on the substrate carbon (Table 1). Thus, in PHF8 


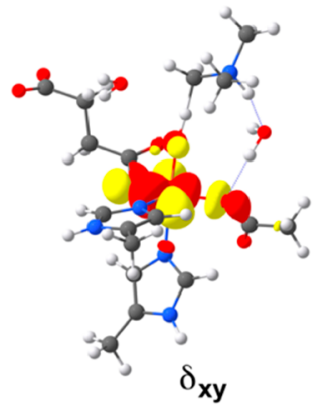

(1.0)

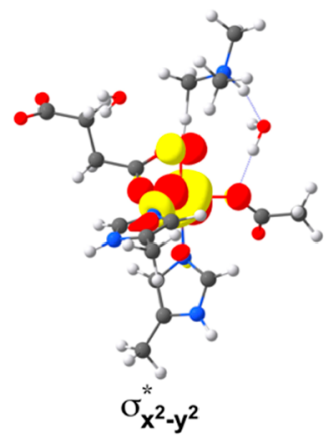

(1.0)

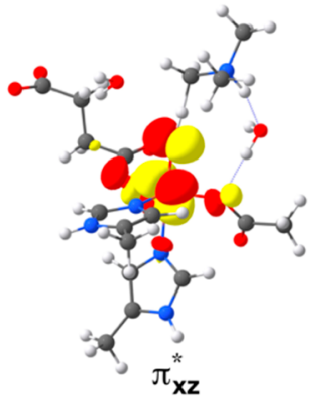

$(1.0)$

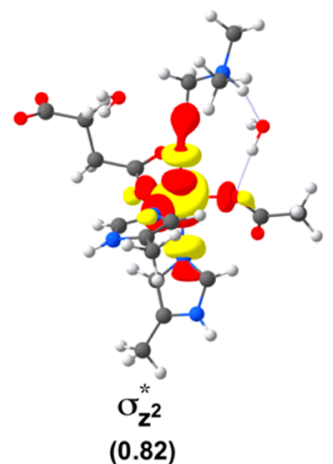

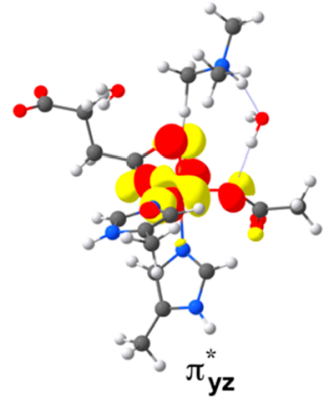

(1.0)

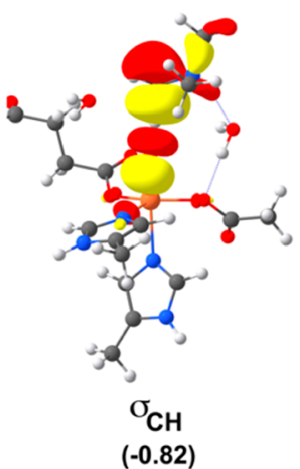

Figure 7. Transition state spin natural orbitals (SNO) of the HAT (TS6) from C-H with orbital occupancies in the bracket.

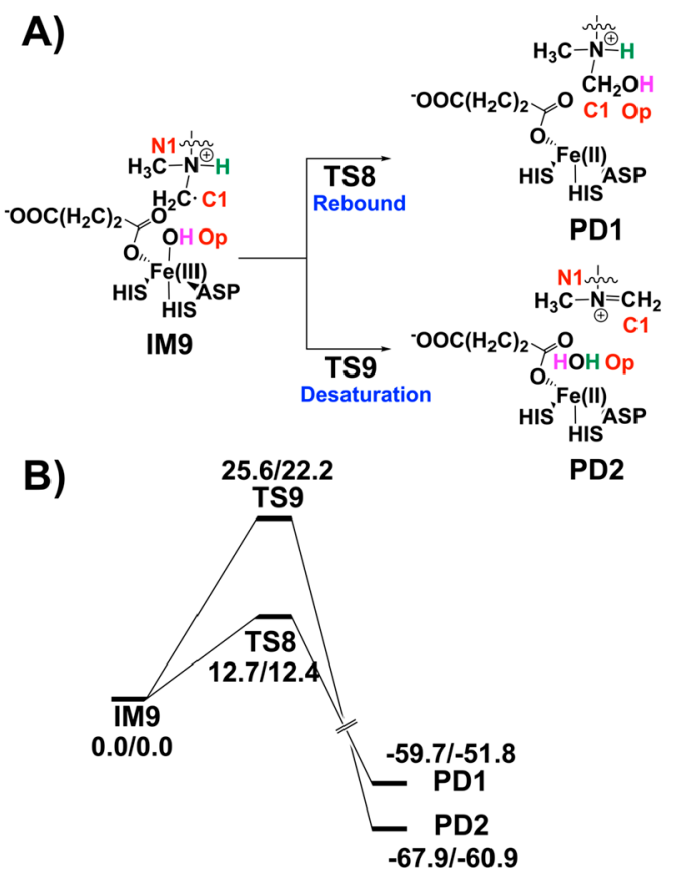

C)
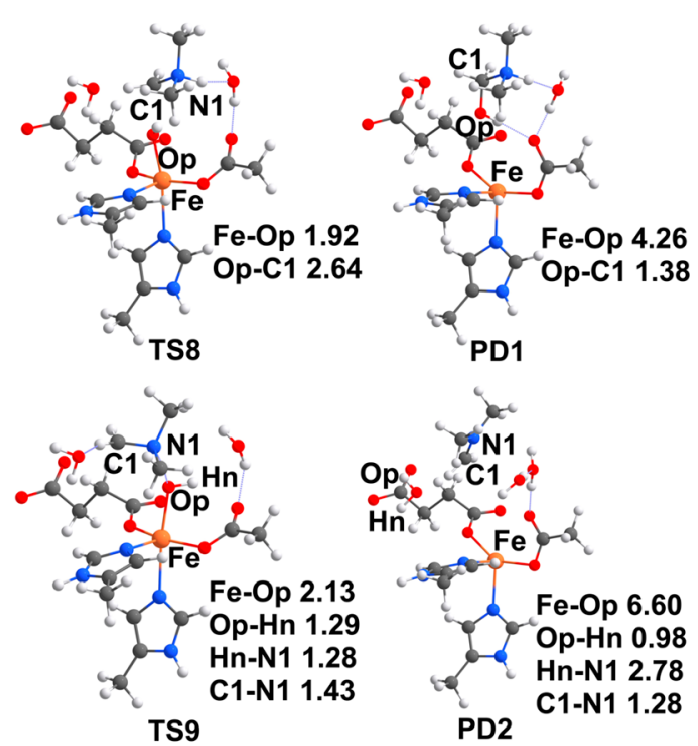

Figure 8. (A) Possible reaction pathways after HAT for the rebound (IM9-TS8-PD1) and desaturation (IM9-TS9-PD2) mechanisms. (B) Potential energy surface for the rebound and desaturation mechanisms. Energies are reported in $\mathrm{kcal} / \mathrm{mol}$ at the $\mathrm{QM}(\mathrm{B} 2) / \mathrm{MM} / \mathrm{QM}(\mathrm{B} 2+\mathrm{ZPE})$ / MM level of theory. (C) QM active site geometries of selected transition states and products in the hydrogen atom transfer step of PHF8 catalysis from QM/MM calculations. Bond lengths are in angstroms.

(RC2), electron transfer occurs via a $\sigma$ channel to the ferryloxo $\sigma_{z}^{*} z^{2}$ orbital.

To explore the effect of additional water coordination at the ferryl-oxo stage, including on the hydrogen atom transfer reaction barrier, we performed a $\mathrm{QM} / \mathrm{MM}$ potential energy scan starting from the six-coordinated ferryl-oxo IM7. The reaction barrier for hydrogen abstraction from methyl $\mathrm{C}-\mathrm{H}$ of the substrate was found to be $21.7 \mathrm{kcal} / \mathrm{mol}$ at the
$\mathrm{QM}(\mathrm{B} 2+\mathrm{ZPE}) / \mathrm{MM}$ level of theory for the ferryl-oxo with additional water. The activation barrier for hydrogen atom transfer from the six-coordinated ferryl-oxo species is thus within the range of activation energy obtained from the fivecoordinated ferryl-oxo intermediate.

3.8. Following HAT, the Reaction Proceeds through Rebound Rather than Desaturation. While the ratelimiting step for demethylation by PHF8 (at least once the 
substrate is bound at the active site) is hydrogen abstraction, the following step raises another interesting mechanistic question. The product formed after HAT, i.e., the ferrichydroxyl species (IM9), can either undergo a rebound reaction to form the hydroxylated product or produce a desaturated product by abstracting the second hydrogen from $\mathrm{NH}$ to give an iminium ion which could then undergo hydrolysis (Figure $8 \mathrm{~A})$. This mechanistic dilemma manifests itself in other $2 \mathrm{OG}$ demethylases and some other related enzymes (in some cases, both hydroxylation and desaturation are observed; ${ }^{12}$ a synthetic model of the non-heme oxygenases has shown desaturation to be a feasible mechanistic option). ${ }^{105}$ The factors governing the $\mathrm{Fe}(\mathrm{III})-\mathrm{OH}$ species to act as hydroxylase or desaturase have been shown to depend on bond strength, coordination-sphere, and ligand sphere flexibility, and steric effects. ${ }^{105,106}$

In the absence of experimental data on enzyme-bound hydroxylated intermediates in KDMs catalysis, we explored the effects of the protein environment on the selection of the reaction path after the HAT; we investigated the reactivity of the ferric-hydroxyl product formed after HAT (IM9) to undergo rebound hydroxylation and desaturation (Figure 8A). The potential energy profiles for rebound (IM9-TS8-PD1) and desaturation (IM9-TS9-PD2) reactions are shown in Figure $8 \mathrm{~B}$. The calculated activation energies are 12.4 and 22.2 $\mathrm{kcal} / \mathrm{mol}$ for TS8 and TS9 at the QM(B2+ZPE)/MM level of theory for the rebound and the desaturation reaction, respectively. The D3 dispersion corrected energies also support the rebound over the desaturation mechanism (see Table S13 and Table S15 for spin densities). The calculations show a clear preference for a rebound process in the presence of the PHF8 protein environment. Steric effects are a major factor helping favor a rebound over a desaturation pathway, including those involving I191. As seen earlier for calculations on the hydrogen atom abstraction step (Figure 4), the substrate conformation does not make $\mathrm{N}-\mathrm{H}$ easily accessible to the IM9 intermediate because of steric constraints; in IM9 it is stabilized via hydrogen bonding (with iron-bound aspartate D249), thus rendering desaturation unfavorable (Figure 8C). The hydroxyl group in IM9 might have reduced electrophilicity compared to a ferryl-oxo group (the spin density on the oxygen atom of the hydroxyl group reduces to 0.22 after HAT from a spin density of 0.55 ), making it a bad electrophile for a second hydrogen abstraction step/desaturation from the $\mathrm{NH}$ bond. Radical delocalization is also an important factor in determining whether rebound or desaturation occurs; if the radical is relatively delocalized, desaturation is more preferred; if the radical is localized, then rebound is preferred. ${ }^{105}$ The electron density of $(-1.04)$ on the carbon atom in IM9 shows the radical is localized on the carbon-atom, making rebound more likely. Thus, steric effects by the protein environment, hydrogen-bond stabilization of the $\mathrm{NH}$ species with ironbound aspartate D249, and radical localization contribute to the rebound reaction being energetically preferred over desaturation in PHF8 catalysis.

\section{CONCLUSIONS}

We used multiple microsecond $\mathrm{MDs}$ and $\mathrm{QM} / \mathrm{MM}$ simulations to explore the catalytic strategy of the non-heme $\mathrm{Fe}(\mathrm{II})$ and 2OG-dependent histone lysine demethylase PHF8, which is involved in key epigenetic processes. Similarly to other 2OG-dependent non-heme enzymes, PHF8 follows an $\mathrm{O}_{2}$ activation pathway wherein a ferric-superoxo intermediate reacts with the Fe-complexed C2 carbonyl group of $2 \mathrm{OG}$ leading to decarboxylation and formation of a ferryl-oxo complex and succinate. If generated from a starting complex in which the 2OG $\mathrm{C} 1$ carboxylate is complexed to the Fe trans to His247, the so generated ferryl-oxo complex has an "off-line" geometry, i.e., is unproductive for catalysis. This unproductive species has been proposed to undergo a ferryl-flip via oxygen atom exchange with a water molecule to form an "in-line" productive ferryl-oxo species (trans to His319); however, our calculations indicate that this process is energetically unfavorable. Instead, we propose that at a five-coordinate 2OG-bound state prior to dioxygen binding, 2OG flips from an "off-line" to an "in-line" coordination geometry, in a process with a minimal energy barrier, thus enabling the subsequent, direct production of "in-line" ferric-superoxo, succinyl-peroxo, and ferryl-oxo intermediates. The "in-line" ferryl-oxo intermediate is thus in a productive orientation with respect to the substrate for the subsequent reaction steps.

$\mathrm{QM} / \mathrm{MM}$ calculations imply that hydrogen abstraction occurs from a $\mathrm{C}-\mathrm{H}$ bond of substrate $\mathrm{N}^{\varepsilon}$-methyl group; by contrast, hydrogen abstraction from $\mathrm{N}^{\varepsilon}-\mathrm{H}$ is a highly energyinefficient process, in part due to the substrate conformation relative to the ferryl-oxo species and steric repulsion from the second sphere residue I191. By analyzing multiple reaction paths for the HAT step, we show that hydrogen abstraction proceeds via a $\sigma$ channel. The $\mathrm{QM} / \mathrm{MM}$ calculations in the presence of the protein environment of PHF8 show that the rebound pathway is more energetically favored than desaturation due to the substrate conformation, second sphere interactions, and reduced reactivity of $\mathrm{Fe}-\mathrm{OH}$ species generated after HAT.

Overall our studies provide key insights into the atomistic effects of the protein environment on the reaction path of PHF8 and distinguish between alternative mechanistic proposals for hydroxylation/demethylation of the substrate $\mathrm{N}^{\varepsilon}$-methyl group. Presently, with rare exceptions (e.g., meldonium ${ }^{107}$ ), most $20 \mathrm{O}$ oxygenase inhibitors, including one recently approved for clinical use, are active site $\mathrm{Fe}$ chelators that compete with 2OG. ${ }^{108,109}$ Such compounds, however, block rather than modulate $20 \mathrm{O}$ oxygenase activity with consequent potential "on target" side effects in the presence of excess inhibitor. We hope that the detailed mechanistic insights presented here for PHF8, as well as ongoing work on other $2 \mathrm{OG}$ oxygenases, will help enable the design of mechanism-based inhibitors of $2 \mathrm{OG}$ oxygenases that modulate kinetics, e.g., by slowing the movement of the $2 \mathrm{OG}$ C1 carboxylate from an "off-line" to an "in-line" geometry.

\section{ASSOCIATED CONTENT}

\section{S Supporting Information}

The Supporting Information is available free of charge at https://pubs.acs.org/doi/10.1021/acscatal.9b04907.

Analysis of molecular dynamics and QM/MM optimized QM geometries with spin densities and partial charges are included (PDF)

\section{AUTHOR INFORMATION}

\section{Corresponding Authors}

*(C.Z.C.) E-mail: christov@mtu.edu.

*(T.G.K.-C.) E-mail: tatyanak@mtu.edu.

ORCID ${ }^{\circ}$

Shobhit S. Chaturvedi: 0000-0003-4977-5600 
Rajeev Ramanan: 0000-0002-5879-0768

Nicolai Lehnert: 0000-0002-5221-5498

Christopher J. Schofield: 0000-0002-0290-6565

Tatyana G. Karabencheva-Christova: 0000-0001-8629-4377

Christo Z. Christov: 0000-0002-4481-0246

\section{Notes}

The authors declare no competing financial interest.

\section{ACKNOWLEDGMENTS}

This research was supported by the Michigan Tech Graduate Teaching Assistantship to S.S.C., Michigan Tech start-up grants to T.G.K.-C. and C.Z.C. C.Z.C. acknowledges NSF grant 1904215 (validating the methodology). C.J.S. thanks Cancer Research UK (C8717/A18245) and the Wellcome Trust $(091857 / 7 / 10 / 7)$ for support.

\section{REFERENCES}

(1) Luger, K.; Hansen, J. C. Nucleosome and Chromatin Fiber Dynamics. Curr. Opin. Struct. Biol. 2005, 15, 188-196.

(2) Kouzarides, T. Chromatin Modifications and Their Function. Cell 2007, 128, 693-705.

(3) Allis, C. D.; Jenuwein, T. The Molecular Hallmarks of Epigenetic Control. Nat. Rev. Genet. 2016, 17, 487-500.

(4) Wang, G. G.; Allis, C. D. Misinterpretation” of a Histone Mark Is Linked to Aberrant Stem Cells and Cancer Development. Cell Cycle 2009, 8, 1979-1983.

(5) Chi, P.; Allis, C. D.; Wang, G. G. Covalent Histone Modifications-Miswritten, Misinterpreted and Mis-Erased in Human Cancers. Nat. Rev. Cancer 2010, 10, 457-469.

(6) Ooi, W. F.; Yao, X.; Tan, P.; Teh, B. T. Misregulation of Histone Methylation Regulators in Cancer. DNA and Histone Methylation as Cancer Targets 2017, 221-248.

(7) Bannister, A. J.; Kouzarides, T. Histone Methylation: Recognizing the Methyl Mark. Methods Enzymol. 2003, 376, 269288.

(8) (a) Schofield, C. J.; Hausinger, R. P., Eds. 2-OxoglutarateDependent Oxygenases; The Royal Society of Chemistry: Cambridge, U.K., 2015. (b) Horton, J. R.; Gale, M.; Yan, Q.; Cheng, X. The Molecular Basis of Histone Demethylation. DNA and Histone Methylation as Cancer Targets 2017, 151-219.

(9) Lee, C. T.; Duerre, J. A. Changes in Histone Methylase Activity of Rat Brain and Liver with Ageing. Nature 1974, 251, 240-242.

(10) Byvoet, P.; Shepherd, G. R.; Hardin, J. M.; Noland, B. J. The Distribution and Turnover of Labeled Methyl Groups in Histone Fractions of Cultured Mammalian Cells. Arch. Biochem. Biophys. 1972, $148,558-567$.

(11) Walport, L. J.; Hopkinson, R. J.; Schofield, C. J. Mechanisms of Human Histone and Nucleic Acid Demethylases. Curr. Opin. Chem. Biol. 2012, 16, 525-534.

(12) Hausinger, R. P. Fe(II) $/ \alpha$-Ketoglutarate-Dependent Hydroxylases and Related Enzymes. Crit. Rev. Biochem. Mol. Biol. 2004, 39, 21-68.

(13) Aik, W. S.; McDonough, M. A.; Thalhammer, A.; Chowdhury, R.; Schofield, C. J. Role of the Jelly-Roll Fold in Substrate Binding by 2-Oxoglutarate Oxygenases. Curr. Opin. Struct. Biol. 2012, 22, 691700.

(14) Torabifard, H.; Cisneros, G. A. Computational Investigation of O2 Diffusion through an Intra-Molecular Tunnel in AlkB; Influence of Polarization on O2 Transport. Chem. Sci. 2017, 8, 6230-6238.

(15) Cortopassi, W. A.; Simion, R.; Honsby, C. E.; França, T. C. C.; Paton, R. S. Dioxygen Binding in the Active Site of Histone Demethylase JMJD2A and the Role of the Protein Environment. Chem. - Eur. J. 2015, 21, 18983-18992.

(16) Yue, W. W.; Hozjan, V.; Ge, W.; Loenarz, C.; Cooper, C. D. O.; Schofield, C. J.; Kavanagh, K. L.; Oppermann, U.; McDonough, M. A.
Crystal Structure of the PHF8 Jumonji Domain, an N $\varepsilon$-Methyl Lysine Demethylase. FEBS Lett. 2010, 584, 825-830.

(17) Horton, J. R.; Upadhyay, A. K.; Qi, H. H.; Zhang, X.; Shi, Y.; Cheng, X. Enzymatic and Structural Insights for Substrate Specificity of a Family of Jumonji Histone Lysine Demethylases. Nat. Struct. Mol. Biol. 2010, 17, 38-44.

(18) Björkman, M.; Östling, P.; Härmä, V.; Virtanen, J.; Mpindi, J. P.; Rantala, J.; Mirtti, T.; Vesterinen, T.; Lundin, M.; Sankila, A.; Rannikko, A.; Kaivanto, E.; Kohonen, O.; Kallioniemi, O.; Nees, M. Systematic Knockdown of Epigenetic Enzymes Identifies a Novel Histone Demethylase PHF8 Overexpressed in Prostate Cancer with an Impact on Cell Proliferation, Migration and Invasion. Oncogene 2012, 31, 3444-3456.

(19) Ma, Q.; Chen, Z.; Jia, G.; Lu, X.; Xie, X.; Jin, W. The Histone Demethylase PHF8 Promotes Prostate Cancer Cell Growth by Activating the Oncomir MiR-125b. OncoTargets Ther. 2015, 8, 19791988.

(20) Wang, Q.; Ma, S.; Song, N.; Li, X.; Liu, L.; Yang, S.; Ding, X.; Shan, L.; Zhou, X.; Su, D.; Wang, Y.; Zhang, Q.; Liu, X.; Yu, N.; Zhang, K.; Shang, Y.; Yao, Z.; Shi, L. Stabilization of Histone Demethylase PHF8 by USP7 Promotes Breast Carcinogenesis. J. Clin. Invest. 2016, 126, 2205-2220.

(21) Zhu, G.; Liu, L.; She, L.; Tan, H.; Wei, M.; Chen, C.; Su, Z.; Huang, D.; Tian, Y.; Qiu, Y.; Liu, Y.; Zhang, X. Elevated Expression of Histone Demethylase PHF8 Associates with Adverse Prognosis in Patients of Laryngeal and Hypopharyngeal Squamous Cell Carcinoma. Epigenomics 2015, 7, 143-153.

(22) Shen, Y.; Pan, X.; Zhao, H. The Histone Demethylase PHF8 Is an Oncogenic Protein in Human Non-Small Cell Lung Cancer. Biochem. Biophys. Res. Commun. 2014, 451, 119-125.

(23) Sun, X.; Qiu, J. J.; Zhu, S.; Cao, B.; Sun, L.; Li, S.; Li, P.; Zhang, S.; Dong, S. Oncogenic Features of PHF8 Histone Demethylase in Esophageal Squamous Cell Carcinoma. PLoS One 2013, 8, No. e77353.

(24) Loenarz, C.; Ge, W.; Coleman, M. L.; Rose, N. R.; Cooper, C. D. O.; Klose, R. J.; Ratcliffe, P. J.; Schofield, C. J. PHF8, a Gene Associated with Cleft Lip/Palate and Mental Retardation, Encodes for an $\mathrm{N} \varepsilon$-Dimethyl Lysine Demethylase. Hum. Mol. Genet. 2010, 19, $217-222$.

(25) Abidi, F. E.; Miano, M. G.; Murray, J. C.; Schwartz, C. E. A Novel Mutation in the PHF8 Gene Is Associated with X-Linked Mental Retardation with Cleft Lip/Cleft Palate. Clin. Genet. 2007, 72, $19-22$.

(26) Koivisto, A. M.; Ala-Mello, S.; Lemmelä, S.; Komu, H. A.; Rautio, J.; Järvelä, I. Screening of Mutations in the PHF8 Gene and Identification of a Novel Mutation in a Finnish Family with XLMR and Cleft Lip/Cleft Palate. Clin. Genet. 2007, 72, 145-149.

(27) Laumonnier, F.; Holbert, S.; Ronce, N.; Faravelli, F.; Lenzner, S.; Schwartz, C. E.; Lespinasse, J.; Van Esch, H.; Lacombe, D.; Goizet, C.; Phan-Dinh, T. F.; van Bokhoven, H.; Fryns, J. P.; Chelly, J.; Ropers, H. H.; Moraine, C.; Hamel, B. C.; Briault, S. Mutations in PHF8 Are Associated with X Linked Mental Retardation and Cleft Lip/Cleft Palate. J. Med. Genet. 2005, 42, 780-786.

(28) Chaturvedi, S. S.; Ramanan, R.; Waheed, S. O.; Ainsley, J.; Evison, M.; Ames, J. M.; Schofield, C. J.; Karabencheva-Christova, T. G.; Christov, C. Z. Conformational Dynamics Underlies Different Functions of Human KDM7 Histone Demethylases. Chem. - Eur. J. 2019, 25, 5422-5426.

(29) Hopkinson, R. J.; Hamed, R. B.; Rose, N. R.; Claridge, T. D. W.; Schofield, C. J. Monitoring the Activity of 2-Oxoglutarate Dependent Histone Demethylases by NMR Spectroscopy: Direct Observation of Formaldehyde. ChemBioChem 2010, 11, 506-510.

(30) Zhang, Z.; Ren, J.; Harlos, K.; McKinnon, C. H.; Clifton, I. J.; Schofield, C. J. Crystal Structure of a Clavaminate Synthase-Fe(II)-2Oxoglutarate-Substrate-NO Complex: Evidence for Metal Centred Rearrangements. FEBS Lett. 2002, 517, 7-12.

(31) Elkins, J. M.; Ryle, M. J.; Clifton, I. J.; Dunning Hotopp, J. C.; Lloyd, J. S.; Burzlaff, N. I.; Baldwin, J. E.; Hausinger, R. P.; Roach, P. L. X-Ray Crystal Structure of Escherichia Coli Taurine/ $\alpha$ - 
Ketoglutarate Dioxygenase Complexed to Ferrous Iron and Substrates. Biochemistry 2002, 41, 5185-5192.

(32) Dann, C. E.; Bruick, R. K.; Deisenhofer, J. Structure of FactorInhibiting Hypoxia-Inducible Factor 1: An Essential Asparaginyl Hydroxylase Involved in the Hypoxic Response Pathway. Proc. Natl. Acad. Sci. U. S. A. 2002, 99, 15351-15356.

(33) Clifton, I. J.; Doan, L. X.; Sleeman, M. C.; Topf, M.; Suzuki, H.; Wilmouth, R. C.; Schofield, C. J. Crystal Structure of Carbapenem Synthase (CarC). J. Biol. Chem. 2003, 278, 20843-20850.

(34) Wilmouth, R. C.; Turnbull, J. J.; Welford, R. W. D.; Clifton, I. J.; Prescott, A. G.; Schofield, C. J. Structure and Mechanism of Anthocyanidin Synthase from Arabidopsis Thaliana. Structure 2002, 10, 93-103.

(35) Yu, B.; Edstrom, W. C.; Benach, J.; Hamuro, Y.; Weber, P. C.; Gibney, B. R.; Hunt, J. F. Crystal Structures of Catalytic Complexes of the Oxidative DNA/RNA Repair Enzyme AlkB. Nature 2006, 439, 879-884.

(36) Chang, W. C.; Li, J.; Lee, J. L.; Cronican, A. A.; Guo, Y. Mechanistic Investigation of a Non-Heme Iron Enzyme Catalyzed Epoxidation in (-)-4'-Methoxycyclopenin Biosynthesis. J. Am. Chem. Soc. 2016, 138, 10390-10393.

(37) Puri, M.; Company, A.; Sabenya, G.; Costas, M.; Que, L. Oxygen Atom Exchange between $\mathrm{H} 2 \mathrm{O}$ and Non-Heme Oxoiron(IV) Complexes: Ligand Dependence and Mechanism. Inorg. Chem. 2016, $55,5818-5827$.

(38) Company, A.; Prat, I.; Frisch, J. R.; Mas-Ballesté, D. R.; Güell, M.; Juhász, G.; Ribas, X.; Münck, D. E.; Luis, J. M.; Que, L., Jr.; Costas, M. Modeling the Cis-Oxo-Labile Binding Site Motif of NonHeme Iron Oxygenases: Water Exchange and Oxidation Reactivity of a Non-Heme Iron(IV)-Oxo Compound Bearing a Tripodal Tetradentate Ligand. Chem. - Eur. J. 2011, 17, 1622-1634.

(39) Song, X.; Lu, J.; Lai, W. Mechanistic Insights into Dioxygen Activation, Oxygen Atom Exchange and Substrate Epoxidation by AsqJ Dioxygenase from Quantum Mechanical/Molecular Mechanical Calculations. Phys. Chem. Chem. Phys. 2017, 19, 20188-20197.

(40) Borowski, T.; Noack, H.; Radoń, M.; Zych, K.; Siegbahn, P. E. M. Mechanism of Selective Halogenation by SyrB2: A Computational Study. J. Am. Chem. Soc. 2010, 132, 12887-12898.

(41) Welford, R. W. D.; Kirkpatrick, J. M.; McNeill, L. A.; Puri, M.; Oldham, N. J.; Schofield, C. J. Incorporation of Oxygen into the Succinate Co-Product of Iron(II) and 2-Oxoglutarate Dependent Oxygenases from Bacteria, Plants and Humans. FEBS Lett. 2005, 579, 5170-5174.

(42) Yu, L.; Wang, Y.; Huang, S.; Wang, J.; Deng, Z.; Zhang, Q.; Wu, W.; Zhang, X.; Liu, Z.; Gong, W.; Chen, Z. Structural Insights into a Novel Histone Demethylase PHF8. Cell Res. 2010, 20, 166173.

(43) Rose, N. R.; Woon, E. C. Y.; Tumber, A.; Walport, L. J.; Chowdhury, R.; Li, X. S.; King, O. N. F.; Lejeune, C.; Ng, S. S.; Krojer, T.; Chan, M. C.; Rydzik, A. M.; Hopkinson, R. J.; Che, K. H.; Daniel, M.; Strain-Damerell, C.; Gileadi, C.; Leung, I. K.; Dunford, J.; Yeoh, K. K.; Ratcliffe, P. J.; Burgess-Brown, N.; von Delft, F.; Muller, S.; Marsden, B.; Brennan, P. E.; McDonough, M. A.; Oppermann, U.; Klose, R. J.; Schofield, C. J.; Kawamura, A.; et al. Plant Growth Regulator Daminozide Is a Selective Inhibitor of Human KDM2/7 Histone Demethylases. J. Med. Chem. 2012, 55, 6639-6643.

(44) Alberro, N.; Torrent-Sucarrat, M.; Arrastia, I.; Arrieta, A.; Cossío, F. P. Two-State Reactivity of Histone Demethylases Containing Jumonji-C Active Sites: Different Mechanisms for Different Methylation Degrees. Chem. - Eur. J. 2017, 23, 137-148.

(45) Kovaleva, E. G.; Lipscomb, J. D. Crystal Structures of Fe2+ Dioxygenase Superoxo, Alkylperoxo, and Bound Product Intermediates. Science 2007, 316, 453-457.

(46) McCusker, K. P.; Klinman, J. P. Modular Behavior of TauD Provides Insight into the Origin of Specificity in Alpha-KetoglutarateDependent Nonheme Iron Oxygenases. Proc. Natl. Acad. Sci. U. S. A. 2009, 106, 19791-19795.

(47) Schlichting, I.; Berendzen, J.; Chu, K.; Stock, A. M.; Maves, S. A.; Benson, D. E.; Sweet, R. M.; Ringe, D.; Petsko, G. A.; Sligar, S. G.
The Catalytic Pathway of Cytochrome P450cam at Atomic Resolution. Science 2000, 287, 1615-1622.

(48) Webb, B.; Sali, A. Comparative Protein Structure Modeling Using MODELLER. Curr. Protoc. Bioinforma. 2016, 54, 5.6.1-5.6.37.

(49) Dennington, R.; Keith, T.; Millam, J. Gauss View, Version 5. Semichem Inc.: Shawnee Mission, KS, 2016.

(50) Case, D. A.; Betz, R. M.; Cerutti, D. S.; Cheatham, T. E.; Daeden, T. A.; Duke, R. E.; Giese, T. J.; Gohlke, H.; Goetz, A. W.; Homeyer, N.; Izadi, S.; Janowski, P.; Kaus, J.; Kovalenko, A.; Lee, T. S.; LeGrand, S.; Li, P.; Lin, C.; Luchko, T.; Luo, R.; Mermelstein, D.; Merz, K. M.; Monard, G.; Nguyen, H.; Nguyen, H. T.; Omelyan, I.; Onufriev, A.; Roe, D. R.; Roitberg, A.; Sagui, C.; Simmerling, C. L.; Botello-Smith, W. M.; Swails, J.; Walker, R. C.; Wang, J.; Wolf, R. M.; Wu, X.; Xiao, L.; Kollman, P. A. AMBER 2016; University of California: San Francisco, CA, 2016.

(51) Gordon, J. C.; Myers, J. B.; Folta, T.; Shoja, V.; Heath, L. S.; Onufriev, A. H++: A Server for Estimating PKas and Adding Missing Hydrogens to Macromolecules. Nucleic Acids Res. 2005, 33, W36871.

(52) Wang, J.; Wang, W.; Kollman, P. A.; Case, D. A. Automatic Atom Type and Bond Type Perception in Molecular Mechanical Calculations. J. Mol. Graphics Modell. 2006, 25, 247-260.

(53) Li, P.; Merz, K. M. MCPB. Py: A Python Based Metal Center Parameter Builder. J. Chem. Inf. Model. 2016, 56, 599-604.

(54) Peters, M. B.; Yang, Y.; Wang, B.; Füsti-Molnár, L.; Weaver, M. N.; Merz, K. M. Structural Survey of Zinc-Containing Proteins and Development of the Zinc AMBER Force Field (ZAFF). J. Chem. Theory Comput. 2010, 6, 2935-2947.

(55) Maier, J. A.; Martinez, C.; Kasavajhala, K.; Wickstrom, L.; Hauser, K. E.; Simmerling, C. Ff14SB: Improving the Accuracy of Protein Side Chain and Backbone Parameters from Ff99SB. J. Chem. Theory Comput. 2015, 11, 3696-3713.

(56) Wong, S. D.; Srnec, M.; Matthews, M. L.; Liu, L. V.; Kwak, Y.; Park, K.; Bell, C. B.; Alp, E. E.; Zhao, J.; Yoda, Y.; Kitao, S.; Seto, M.; Krebs, C.; Bollinger, J. M., Jr.; Solomon, E. I. Elucidation of the $\mathrm{Fe}(\mathrm{IV})=\mathrm{O}$ Intermediate in the Catalytic Cycle of the Halogenase SyrB2. Nature 2013, 499, 320-323.

(57) Waheed, S. O.; Ramanan, R.; Chaturvedi, S. S.; Ainsley, J.; Evison, M.; Ames, J. M.; Schofield, C. J.; Christov, C. Z.; Karabencheva-Christova, T. G. Conformational Flexibility Influences Structure-Function Relationships in Nucleic Acid N-Methyl Demethylases. Org. Biomol. Chem. 2019, 17, 2223-2231.

(58) Jorgensen, W. L.; Chandrasekhar, J.; Madura, J. D.; Impey, R. W.; Klein, M. L. Comparison of Simple Potential Functions for Simulating Liquid Water. J. Chem. Phys. 1983, 79, 926-935.

(59) Darden, T.; York, D.; Pedersen, L. Particle Mesh Ewald: An N. $\log (\mathrm{N})$ Method for Ewald Sums in Large Systems. J. Chem. Phys. 1993, 98, 10089-10092.

(60) Davidchack, R. L.; Handel, R.; Tretyakov, M. V. Langevin Thermostat for Rigid Body Dynamics. J. Chem. Phys. 2009, 130, 234101.

(61) Ryckaert, J. P.; Ciccotti, G.; Berendsen, H. J. Numerical Integration of the Cartesian Equations of Motion of a System with Constraints: Molecular Dynamics of n-Alkanes. J. Comput. Phys. 1977, 23, 327-341.

(62) Berendsen, H. J. C.; Postma, J. P. M.; van Gunsteren, W. F.; DiNola, A.; Haak, J. R. Molecular Dynamics with Coupling to an External Bath. J. Chem. Phys. 1984, 81, 3684-3690.

(63) Roe, D. R.; Cheatham, T. E. PTRAJ and CPPTRAJ: Software for Processing and Analysis of Molecular Dynamics Trajectory Data. J. Chem. Theory Comput. 2013, 9, 3084-3095.

(64) Ylilauri, M.; Pentikäinen, O. T. MMGBSA as a Tool to Understand the Binding Affinities of Filamin-Peptide Interactions. J. Chem. Inf. Model. 2013, 53, 2626-2633.

(65) Grant, B. J.; Rodrigues, A. P. C.; ElSawy, K. M.; McCammon, J. A.; Caves, L. S. D. Bio3d: An R Package for the Comparative Analysis of Protein Structures. Bioinformatics 2006, 22, 2695-2696. 
(66) Metz, S.; Kästner, J.; Sokol, A. A.; Keal, T. W.; Sherwood, P. ChemShell-a Modular Software Package for QM/MM Simulations. Wiley Interdiscip. Rev.: Comput. Mol. Sci. 2014, 4, 101-110.

(67) Ahlrichs, R.; Bär, M.; Häser, M.; Horn, H.; Kölmel, C. Electronic Structure Calculations on Workstation Computers: The Program System Turbomole. Chem. Phys. Lett. 1989, 162, 165-169.

(68) Smith, W.; Yong, C. W.; Rodger, P. M. DL_POLY: Application to Molecular Simulation. Mol. Simul. 2002, 28, 385-471.

(69) Bassan, A.; Borowski, T.; Siegbahn, P. E. M. Quantum Chemical Studies of Dioxygen Activation by Mononuclear NonHeme Iron Enzymes with the 2-His-1-Carboxylate Facial Triad. Dalton Trans. 2004, 20, 3153-3162.

(70) Ye, S.; Riplinger, C.; Hansen, A.; Krebs, C.; Bollinger, J. M.; Neese, F. Electronic Structure Analysis of the Oxygen-Activation Mechanism by Fe II- and $\alpha$-Ketoglutarate (AKG)-Dependent Dioxygenases. Chem. - Eur. J. 2012, 18, 6555-6567.

(71) Wójcik, A.; Radoń, M.; Borowski, T. Mechanism of O2 Activation by $\alpha$-Ketoglutarate Dependent Oxygenases Revisited. A Quantum Chemical Study. J. Phys. Chem. A 2016, 120, 1261-1274.

(72) Xue, J.; Lu, J.; Lai, W. Mechanistic Insights into a Non-Heme 2Oxoglutarate-Dependent Ethylene-Forming Enzyme: Selectivity of Ethylene-Formation versus 1 -Arg Hydroxylation. Phys. Chem. Chem. Phys. 2019, 21, 9957-9968.

(73) Wang, B.; Usharani, D.; Li, C.; Shaik, S. Theory Uncovers an Unusual Mechanism of DNA Repair of a Lesioned Adenine by AlkB Enzymes. J. Am. Chem. Soc. 2014, 136, 13895-13901.

(74) Sherwood, P.; De Vries, A. H.; Guest, M. F.; Schreckenbach, G.; Catlow, C. R. A.; French, S. A.; Sokol, A. A.; Bromley, S. T.; Thiel, W.; Turner, A. J.; Billeter, S.; terstegen, F.; Thiel, S.; Kendrick, J.; Rogers, S. C.; Casci, J.; Watson, M.; King, F.; Karlsen, E.; Sjøvoll, M.; Fahmi, A.; Schafer, A.; Lennartz, S. QUASI: A General Purpose Implementation of the $\mathrm{QM} / \mathrm{MM}$ Approach and Its Application to Problems in Catalysis. J. Mol. Struct.: THEOCHEM 2003, 632, 1-28.

(75) Bakowies, D.; Thiel, W. Hybrid Models for Combined Quantum Mechanical and Molecular Mechanical Approaches. J. Phys. Chem. 1996, 100, 10580-10594.

(76) Schäfer, A.; Horn, H.; Ahlrichs, R. Fully Optimized Contracted Gaussian Basis Sets for Atoms Li to Kr. J. Chem. Phys. 1992, 97, 2571-2577.

(77) Senn, H. M.; Thiel, W. QM/MM Methods for Biological Systems. Atomistic Approaches in Modern Biology 2007, 268, 173-290.

(78) Billeter, S. R.; Turner, A. J.; Thiel, W. Linear Scaling Geometry Optimisation and Transition State Search in Hybrid Delocalised Internal Coordinates. Phys. Chem. Chem. Phys. 2000, 2, 2177-2186.

(79) Grimme, S.; Antony, J.; Ehrlich, S.; Krieg, H. A Consistent and Accurate $\mathrm{Ab}$ Initio Parametrization of Density Functional Dispersion Correction (DFT-D) for the 94 Elements H-Pu. J. Chem. Phys. 2010, 132, 154104.

(80) Krebs, C.; Galonić Fujimori, D.; Walsh, C. T.; Bollinger, J. M. Non-Heme Fe(IV)-Oxo Intermediates. Acc. Chem. Res. 2007, 40, 484-492.

(81) Que, L. The Road to Non-Heme Oxoferryls and Beyond. Acc. Chem. Res. 2007, 40, 493-500.

(82) Hong, S.; Sutherlin, K. D.; Park, J.; Kwon, E.; Siegler, M. A.; Solomon, E. I.; Nam, W. Crystallographic and Spectroscopic Characterization and Reactivities of a Mononuclear Non-Haem Iron(III)-Superoxo Complex. Nat. Commun. 2014, 5, 5440.

(83) Borowski, T.; Bassan, A.; Siegbahn, P. E. M. Mechanism of Dioxygen Activation in 2-Oxoglutarate-Dependent Enzymes: A Hybrid DFT Study. Chem. - Eur. J. 2004, 10, 1031-1041.

(84) Ye, S.; Neese, F. Nonheme Oxo-Iron(IV) Intermediates Form an Oxyl Radical upon Approaching the C-H Bond Activation Transition State. Proc. Natl. Acad. Sci. U. S. A. 2011, 108, 1228-1233.

(85) McCammon, J. A.; Harvey, S. C. Dynamics of Proteins and Nucleic Acids; Cambridge University Press: 1987.

(86) Adcock, S. A.; McCammon, J. A. Molecular Dynamics: Survey of Methods for Simulating the Activity of Proteins. Chem. Rev. 2006, 106, 1589-1615.
(87) Karplus, M.; McCammon, J. A. Molecular Dynamics Simulations of Biomolecules. Nat. Struct. Biol. 2002, 9, 646-652.

(88) Hünenberger, P. H.; Mark, A. E.; van Gunsteren, W. F. Fluctuation and Cross-Correlation Analysis of Protein Motions Observed in Nanosecond Molecular Dynamics Simulations. J. Mol. Biol. 1995, 252, 492-503.

(89) Balsera, M. A.; Wriggers, W.; Oono, Y.; Schulten, K. Principal Component Analysis and Long Time Protein Dynamics. J. Phys. Chem. 1996, 100, 2567-2572.

(90) Mitchell, A. J.; Dunham, N. P.; Martinie, R. J.; Bergman, J. A.; Pollock, C. J.; Hu, K.; Allen, B. D.; Chang, W. C.; Silakov, A.; Bollinger, J. M.; Krebs, C.; Boal, A. K. Visualizing the Reaction Cycle in an Iron(II)- and 2-(Oxo)-Glutarate-Dependent Hydroxylase. J. Am. Chem. Soc. 2017, 139, 13830-13836.

(91) Riggs-Gelasco, P. J.; Price, J. C.; Guyer, R. B.; Brehm, J. H.; Barr, E. W.; Bollinger, J. M.; Krebs, C. EXAFS Spectroscopic Evidence for an $\mathrm{Fe}=\mathrm{O}$ Unit in the $\mathrm{Fe}(\mathrm{IV})$ Intermediate Observed during Oxygen Activation by Taurine: $\alpha$-Ketoglutarate Dioxygenase. J. Am. Chem. Soc. 2004, 126, 8108-8109.

(92) Galonić Fujimori, D.; Barr, E. W.; Matthews, M. L.; Koch, G. M.; Yonce, J. R.; Walsh, C. T.; Bollinger, J. M.; Krebs, C.; RiggsGelasco, P. J. Spectroscopic Evidence for a High-Spin Br-Fe(IV)-OxO Intermediate in the $\alpha$-Ketoglutarate-Dependent Halogenase CytC3 from Streptomyces. J. Am. Chem. Soc. 2007, 129, 13408-13409.

(93) Ryle, M. J.; Padmakumar, R.; Hausinger, R. P. Stopped-Flow Kinetic Analysis of Escherichia Coli Taurine $/ \alpha$-Ketoglutarate Dioxygenase: Interactions with $\alpha$-Ketoglutarate, Taurine, and Oxygen. Biochemistry 1999, 38, 15278-15286.

(94) Rugg, G.; Senn, H. M. Formation and Structure of the Ferryl $[\mathrm{Fe}=\mathrm{O}]$ Intermediate in the Non-Haem Iron Halogenase SyrB2: Classical and QM/MM Modelling Agree. Phys. Chem. Chem. Phys. 2017, 19, 30107-30119.

(95) Quesne, M. G.; Latifi, R.; Gonzalez-Ovalle, L. E.; Kumar, D.; De Visser, S. P. Quantum Mechanics/Molecular Mechanics Study on the Oxygen Binding and Substrate Hydroxylation Step in AlkB Repair Enzymes. Chem. - Eur. J. 2014, 20, 435-446.

(96) Wang, B.; Cao, Z.; Sharon, D. A.; Shaik, S. Computations Reveal a Rich Mechanistic Variation of Demethylation of NMethylated DNA/RNA Nucleotides by FTO. ACS Catal. 2015, 5, 7077-7090.

(97) Cheng, Z.; Cheung, P.; Kuo, A. J.; Yukl, E. T.; Wilmot, C. M.; Gozani, O.; Patel, D. J. A Molecular Threading Mechanism Underlies Jumonji Lysine Demethylase KDM2A Regulation of Methylated H3K36. Genes Dev. 2014, 28, 1758-1771.

(98) Shaik, S.; Chen, H.; Janardanan, D. Exchange-Enhanced Reactivity in Bond Activation by Metal-Oxo Enzymes and Synthetic Reagents. Nat. Chem. 2011, 3, 19-27.

(99) Solomon, E. I.; Light, K. M.; Liu, L. V.; Srnec, M.; Wong, S. D. Geometric and Electronic Structure Contributions to Function in Non-Heme Iron Enzymes. Acc. Chem. Res. 2013, 46, 2725-2739.

(100) Geng, C.; Ye, S.; Neese, F. Analysis of Reaction Channels for Alkane Hydroxylation by Nonheme Iron(IV)-Oxo Complexes. Angew. Chem., Int. Ed. 2010, 49, 5717-5720.

(101) Torabifard, H.; Cisneros, G. A. Insight into Wild-Type and T1372E TET2-Mediated 5hmC Oxidation Using Ab Initio QM/MM Calculations. Chem. Sci. 2018, 9, 8433-8445.

(102) Fang, D.; Cisneros, G. A. Alternative Pathway for the Reaction Catalyzed by DNA Dealkylase AlkB from Ab Initio QM/MM Calculations. J. Chem. Theory Comput. 2014, 10, 5136-5148.

(103) Ye, S.; Neese, F. Quantum Chemical Studies of C-H Activation Reactions by High-Valent Nonheme Iron Centers. Curr. Opin. Chem. Biol. 2009, 13, 89-98.

(104) Ye, S.; Geng, C. Y.; Shaik, S.; Neese, F. Electronic Structure Analysis of Multistate Reactivity in Transition Metal Catalyzed Reactions: The Case of C-H Bond Activation by Non-Heme Iron(Iv)Oxo Cores. Phys. Chem. Chem. Phys. 2013, 15, 8017-8030.

(105) Usharani, D.; Janardanan, D.; Shaik, S. Does the TauD Enzyme Always Hydroxylate Alkanes, While an Analogous Synthetic 
Non-Heme Reagent Always Desaturates Them? J. Am. Chem. Soc. 2011, 133, 176-179.

(106) Neidig, M. L.; Solomon, E. I. Structure-Function Correlations in Oxygen Activating Non-Heme Iron Enzymes. Chem. Commun. 2005, 47, 5843-5863.

(107) Leung, I. K. H.; Krojer, T. J.; Kochan, G. T.; Henry, L.; Von Delft, F.; Claridge, T. D. W.; Oppermann, U.; McDonough, M. A.; Schofield, C. J. Structural and Mechanistic Studies on $\gamma$-Butyrobetaine Hydroxylase. Chem. Biol. 2010, 17, 1316-1324.

(108) Rose, N. R.; McDonough, M. A.; King, O. N. F.; Kawamura, A.; Schofield, C. J. Inhibition of 2-Oxoglutarate Dependent Oxygenases. Chem. Soc. Rev. 2011, 40, 4364-4397.

(109) Yeh, T. L.; Leissing, T. M.; Abboud, M. I.; Thinnes, C. C.; Atasoylu, O.; Holt-Martyn, J. P.; Zhang, D.; Tumber, A.; Lippl, K.; Lohans, C. T.; Leung, I. K. H.; Morcrette, H.; Clifton, I. J.; Claridge, T. D. W.; Kawamura, A.; Flashman, E.; Lu, X.; Ratcliffe, P. J.; Chowdhury, R.; Pugh, C. W.; Schofield, C. J. Molecular and Cellular Mechanisms of HIF Prolyl Hydroxylase Inhibitors in Clinical Trials. Chem. Sci. 2017, 8, 7651-7668. 